\title{
Ceramic Matrix Composite (CMC) Thermal Protection Systems (TPS) and Hot Structures for Hypersonic Vehicles ${ }^{1}$
}

\author{
David E. Glass ${ }^{2}$ \\ NASA Langley Research Center, Hampton, VA 23681
}

\begin{abstract}
Thermal protection systems (TPS) and hot structures are required for a range of hypersonic vehicles ranging from ballistic reentry to hypersonic cruise vehicles, both within Earth's atmosphere and non-Earth atmospheres. The focus of this paper is on air breathing hypersonic vehicles in the Earth's atmosphere. This includes single-stage to orbit (SSTO), two-stage to orbit (TSTO) accelerators, access to space vehicles, and hypersonic cruise vehicles. This paper will start out with a brief discussion of aerodynamic heating and thermal management techniques to address the high heating, followed by an overview of TPS for rocket-launched and air-breathing vehicles. The argument is presented that as we move from rocket-based vehicles to air-breathing vehicles, we need to move away from the "insulated airplane" approach used on the Space Shuttle Orbiter to a wide range of TPS and hot structure approaches. The primary portion of the paper will discuss issues and design options for CMC TPS and hot structure components, including leading edges, acreage TPS, and control surfaces. The current state-of-the-art will be briefly discussed for some of the components. The two primary technical challenges impacting the use of CMC TPS and hot structures for hypersonic vehicles are environmental durability and fabrication, and will be discussed briefly.
\end{abstract}

\section{Nomenclature}

$\begin{array}{ll}\text { ACC } & \text { Advanced Carbon/Carbon } \\ \text { C/C } & \text { Carbon/Carbon } \\ \text { CEV } & \text { Crew Exploration Vehicle } \\ \text { CMC } & \text { Ceramic Matrix Composites } \\ \mathrm{CO}_{2} & \text { Carbon Dioxide } \\ \text { CRI } & \text { Conformal Reusable Insulation } \\ \text { CVI } & \text { Chemical Vapor Infiltration } \\ \text { EADS } & \text { European Aeronautic Defense and Space Company } \\ \text { EUCASS } & \text { European Conference for Aerospace Sciences } \\ \text { FEI } & \text { Flexible External Insulation } \\ \text { GTOW } & \text { Gross Take Off Weight } \\ \text { HTV } & \text { Hypersonic Technology Vehicle } \\ \text { IMI } & \text { Internal Multiscreen Insulation } \\ \text { ISS } & \text { International Space Station } \\ \text { MLI } & \text { Multi-Layer Insulation } \\ \text { MMC } & \text { Metal Matrix Composites } \\ \text { MMOD } & \text { Micro-Meteoroid Orbital Debris } \\ \text { NASP } & \text { National AeroSpace Plane } \\ \text { OFI } & \text { Opacified Fibrous Insulation } \\ \text { PMC } & \text { Polymer Matrix Composite } \\ \text { RCC } & \text { Reinforced Carbon/Carbon } \\ \text { ROCCI } & \text { Refractory oxidation-resistant ceramic carbon insulation }\end{array}$

\footnotetext{
1 This paper was originally presented at NASA Headquarters in March 2007 as part of the NASA Aeronautics Research Mission Directorate Technical Seminar series. It is intended as a high level tutorial on CMC TPS and hot structures.

${ }^{2}$ Structural Mechanics and Concepts Branch, MS 190, AIAA Associate Fellow
} 


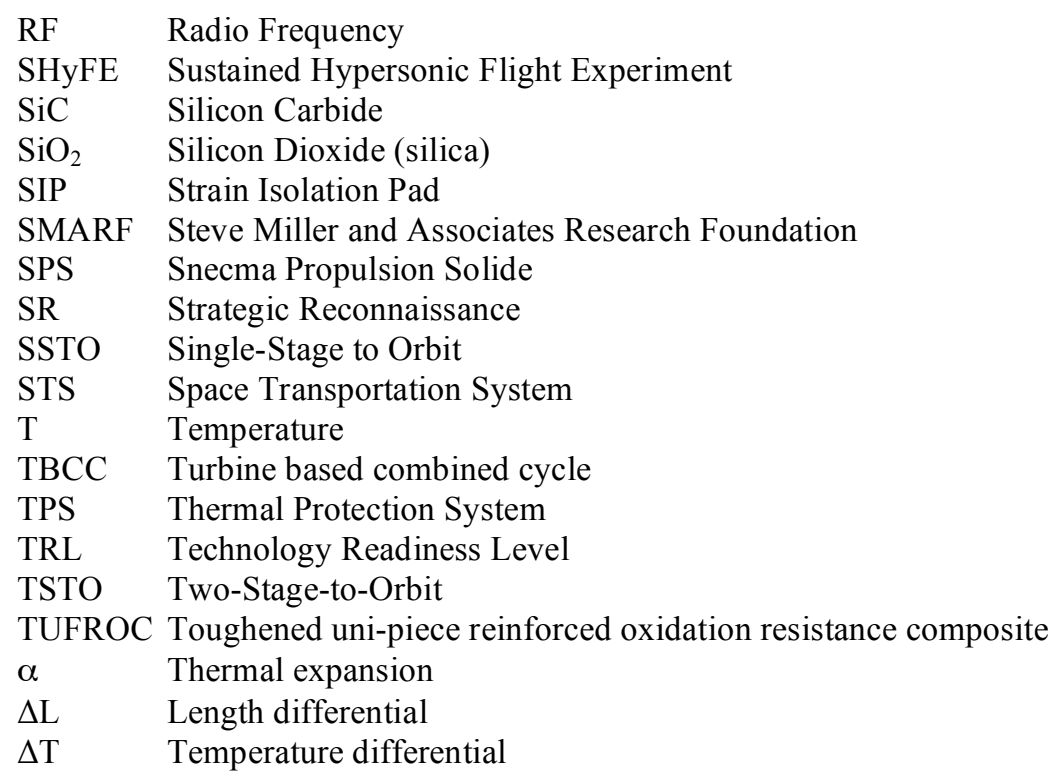

\section{Introduction}

The Hypersonics Project within NASA's Fundamental Aeronautics Program has as one of its reference systems a two-stage-to-orbit (TSTO) access to space vehicle. The concept of operations for this particular class of vehicles is illustrated in Figure 1 as a function of altitude versus Mach number.

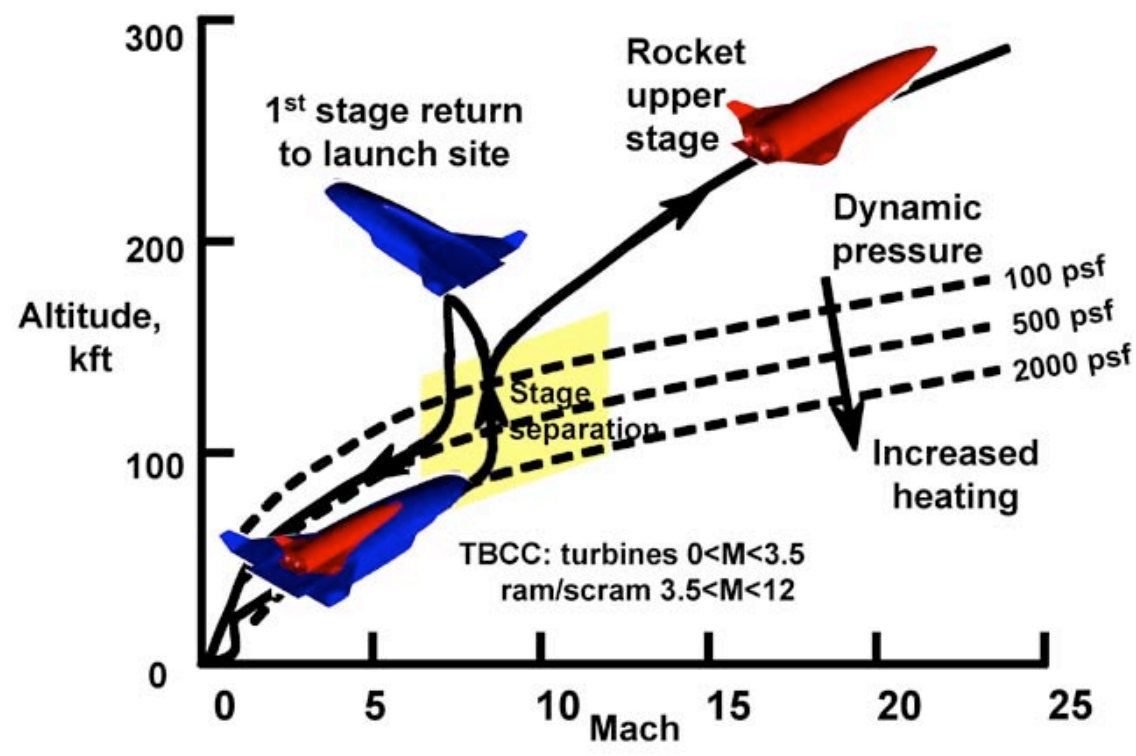

Figure 1. Two-stage to orbit concept of operations as a function of altitude and Mach number.

The TSTO will accelerate to a staging Mach number, indicted by the shaded area, in the range $6 \leq \mathrm{M} \leq 13$. At that point, the first stage and second stage separate. The first stage continues on to orbit powered by the rocket booster and the first stage air-breather returns to the launch site. The propulsion system is a turbine based combined cycle (TBCC) engine with both a turbine, operating up to around $\mathrm{M}=3.5$, and a scram-jet engine operating up to around $\mathrm{M}=12$. The maximum Mach number for the turbine and the minimum and maximum Mach number for the scram-jet are would be dependent on their demonstrated capability. These air-breathing vehicles are usually optimized to accelerate along a constant dynamic pressure. Dynamic pressure is a function of the density of the air times the velocity squared, and the aerodynamic heating is a function of velocity cubed. Lines of constant dynamic pressure shown in Figure 1 correspond to 100 psf, 500 psf, and 2000 psf. 
When flying low in the atmosphere at high velocities, high dynamic pressure and high aerodynamic heating are obtained. One of the challenges for air-breathing vehicles is to balance the desire to fly at a high dynamic pressure, resulting in both increased performance due to increased air flow into the engine and increased heating to the leading edges and airframe, with the desire to limit aerodynamic heating.

Figure 2 shows the heating on a reference one-foot diameter sphere for three different trajectories: a trajectory flown by a crew exploration vehicle (CEV) capsule entering from low earth orbit, a single-stage-to-orbit (SSTO) air breather during ascent, and the Space Shuttle Orbiter during descent. The heating shown in the figure is not the actual heating observed on the vehicle, but is representative of a one-foot diameter sphere. For example, consider a basketball $(\sim 1 \mathrm{ft}$ diameter) and "fly" it through each of the three different trajectories. For the CEV Orion, a very large spike in the heat flux is evident, but for a relatively short time. For the Space Shuttle Orbiter, the heating occurs over a much longer time. The SSTO vehicle has a long duration trajectory and a high heat flux. The rocket boost is shown by the dashed line, and is accelerating the second stage into orbit. For air-breathing vehicles, the radius of the leading edges will be much smaller than one foot. As discussed later in this paper, the heat fluxes will be much higher than shown in Figure 2 because the heat flux is a strong function of the radius.

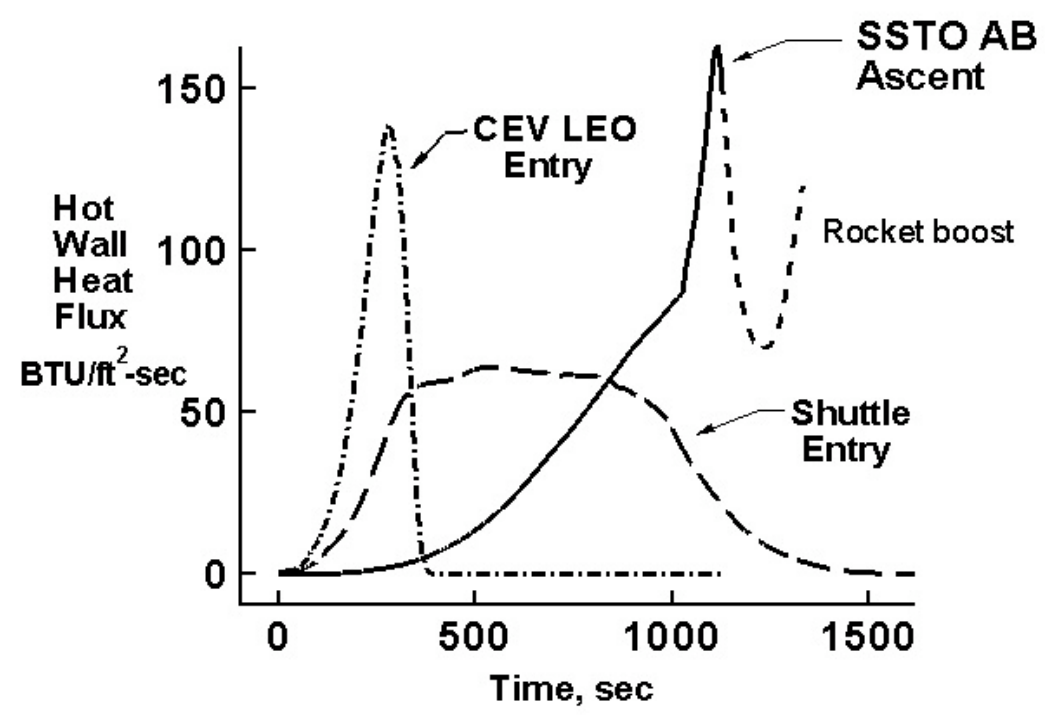

Figure 2. Heating on a reference one-foot diameter sphere for three different trajectories.

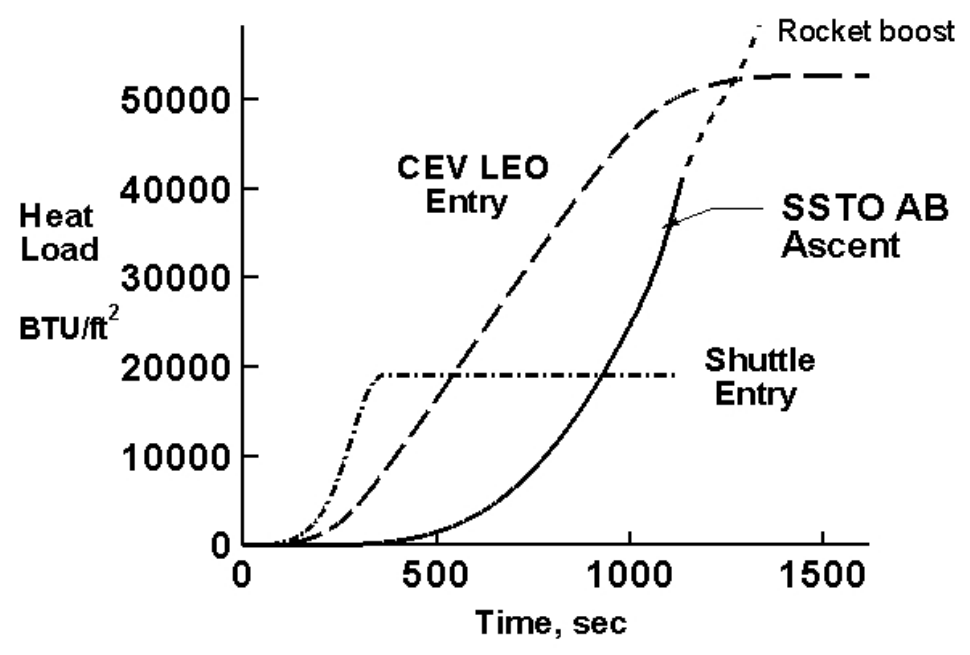

Figure 3. Heat load on a reference one-foot diameter sphere for three different trajectories. 
Heat load is another important parameter. If the heat flux is integrated over time, the heat load is obtained, which is the total heat into the system. The heat load is shown in Figure 3 for the three different trajectories for the CEV capsule, the SSTO air breather, and the Space Shuttle Orbiter on re-entry.

\section{Background}

There are multiple options for dealing with the severe thermal environments encountered during hypersonic flight. Passive, semi-passive, and actively cooled approaches can be utilized. Though the differences between rocket and air-breathing propulsion systems are well known, the differences between rockets and air-breathers can have a significant impact on the TPS and hot structures. As we move toward air-breathing hypersonic vehicles, the severe thermal structural challenges require a new approach to thermal management, one that includes both TPS and hot structures.

\section{A. Thermal Management}

There are three types of thermal management that can be used to cool hypersonic vehicles: passive, semipassive, and active. Passive and semi-passive thermal management may include a phase change. Actively cooled structures would include a pumped coolant.

\section{Passive}

An insulated structure is used for moderate heat fluxes for relatively short times. The figure on the left in Figure 4 shows surface heating, with thermal radiation as the mechanism to remove the heat. The objective of the insulation is to minimize heat reaching the structure, which remains cool. The figure indicates that a small amount of heat is conducted through the insulation to the structure. As an example of an insulated structure, a photograph of the Space Shuttle Orbiter elevons, taken on the STS-116, is shown in Figure 4.
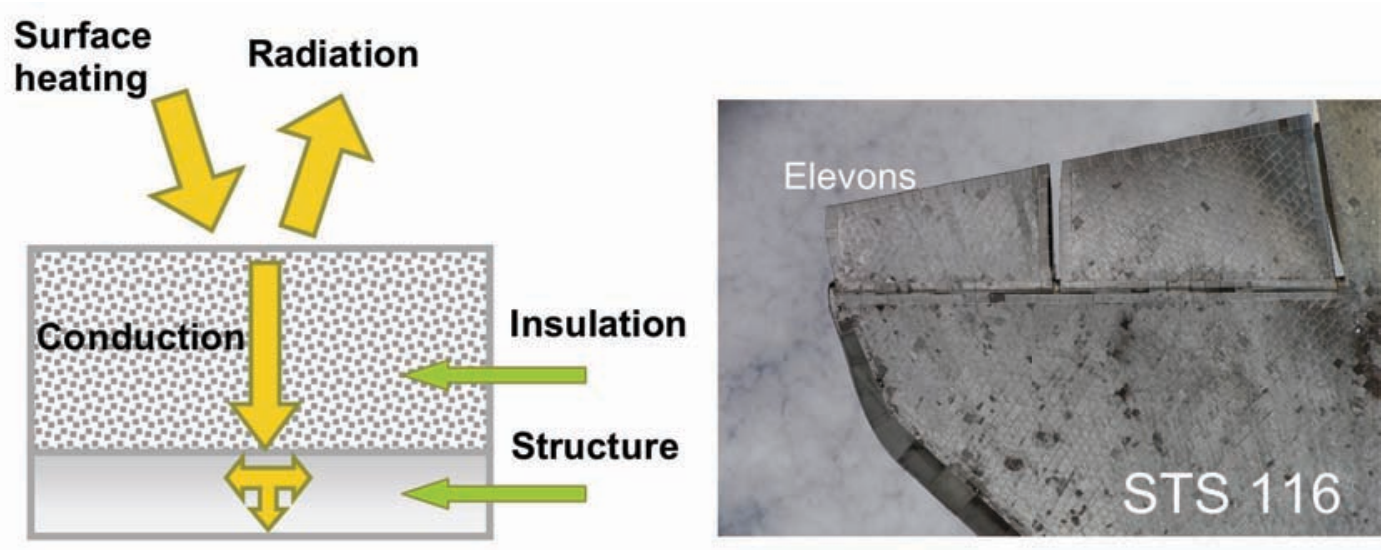

Figure 4. Schematic and photograph (Space Shuttle Orbiter elevons) of an insulated structure.
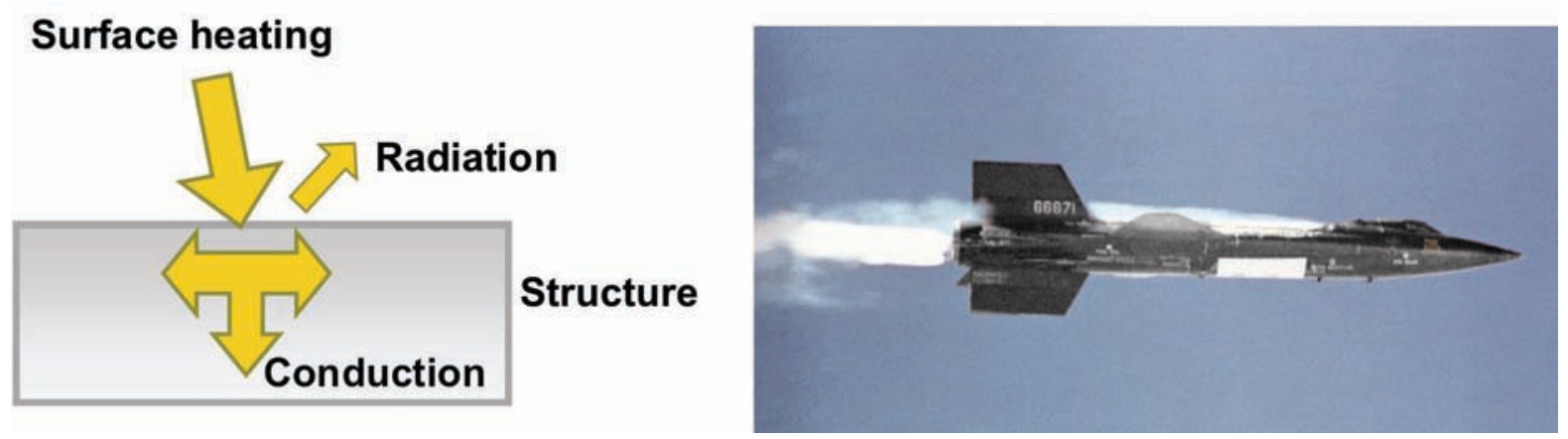

Figure 5. Schematic and photograph (X-15) of a heat sink structure. 
The heat sink structure, shown in Figure 5, is used with a moderate heat flux for a transient situation. When surface heating occurs, some heat is radiated away and some heat is absorbed by the structure. If a heat sink structure is heated for a long period of time, enough heat could be absorbed to overheat the structure. The example shown is with the $\mathrm{X}-15$, where the leading edges utilized a heat sink structure.

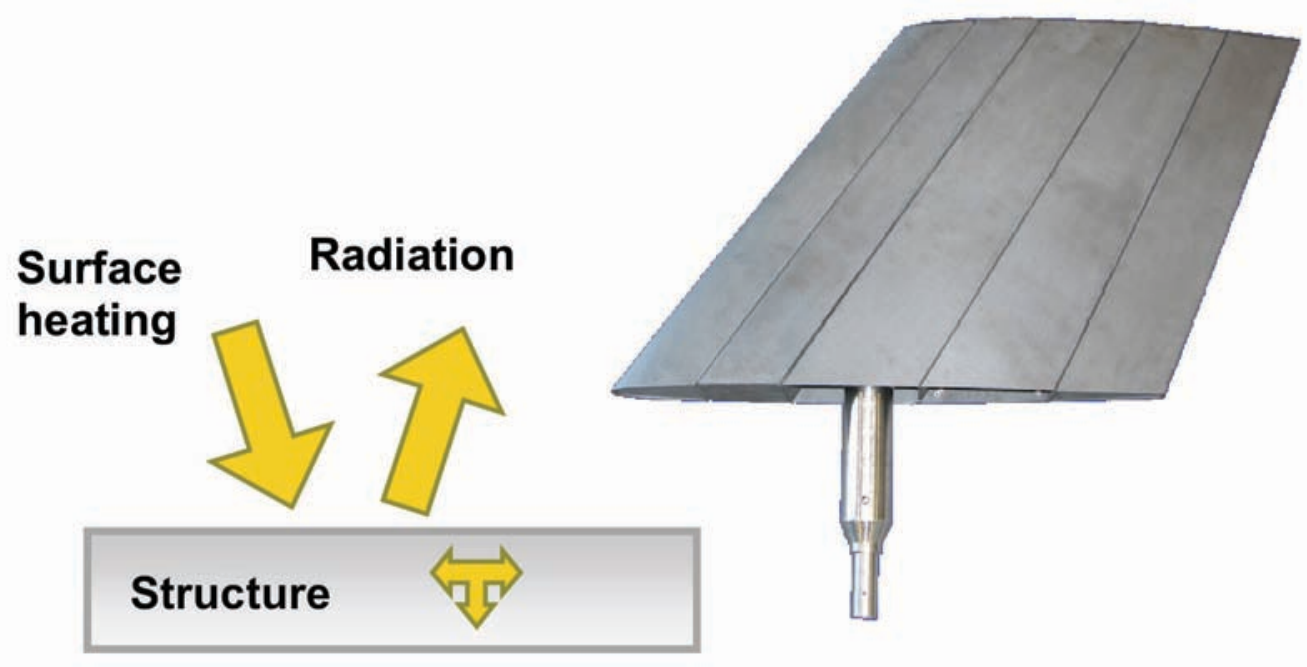

Figure 6. Schematic and photograph of a hot structure.

Figure 6 illustrates a hot structure utilized for moderate heat flux for long periods of time. In contrast to a heat sink structure, hot structures can be used for a higher heat load for long times, allowing the structure to reach steady state conditions. Again, the heat is both radiated away and conducted inward. The entire structure will increase to elevated temperatures.

\section{Semi-Passive}

If high heat fluxes persist for long times, a semi-passive approach may need to be utilized. A heat pipe could be used for high heat fluxes for long periods of time. Heat is transferred by a working fluid to another region of the heat pipe where the heat is radiated away. As with hot structures, the structure operates hot. An example, shown in Figure 7, would be a heat-pipe-cooled wing leading edge.

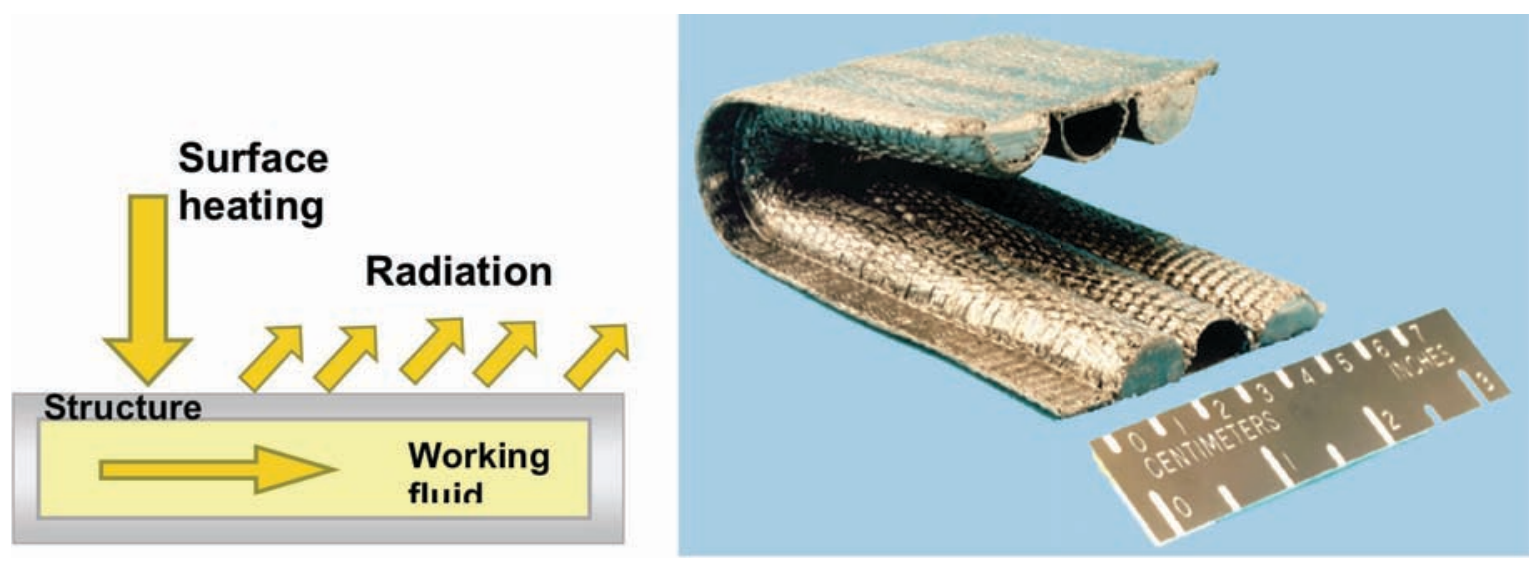

Figure 7. Schematic and photograph illustrating a heat-pipe-cooled leading edge.

Ablation is another semi-passive approach to thermal management. The purpose of the ablator is to keep the structure cool. Ablators are utilized for very high heat fluxes, but for relatively short times, and are for single use. As an example, an image of the Orion capsule is shown in Figure 8, which includes an ablative heat shield. This is the same approach that was used on the Apollo capsule, where the heat is blocked by ablation and the ablator is consumed. Heat is also absorbed by the ablation process. 

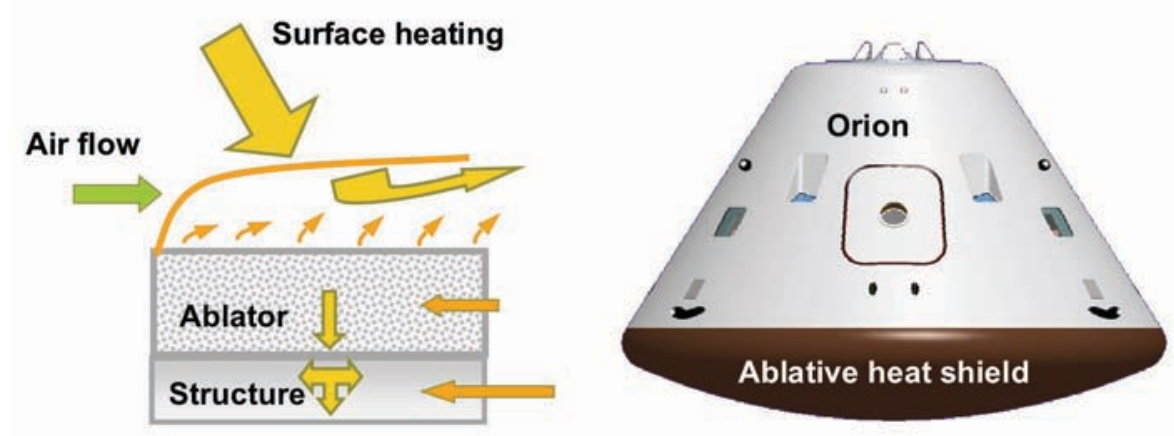

Figure 8. Schematic and illustration of an ablative heat shield.

\section{Active}

For still higher heat fluxes and for long times, active cooling is required. Convective cooling is often utilized for a high heat flux and long times. An example shown in Figure 9 is the Space Shuttle main engine (SSME). Here, convective cooling is used in the propulsion system, where the heat is transferred into the coolant. The coolant heats up and carries the heat away. The structure operates hot but is maintained within its temperature use limits by the active cooling.
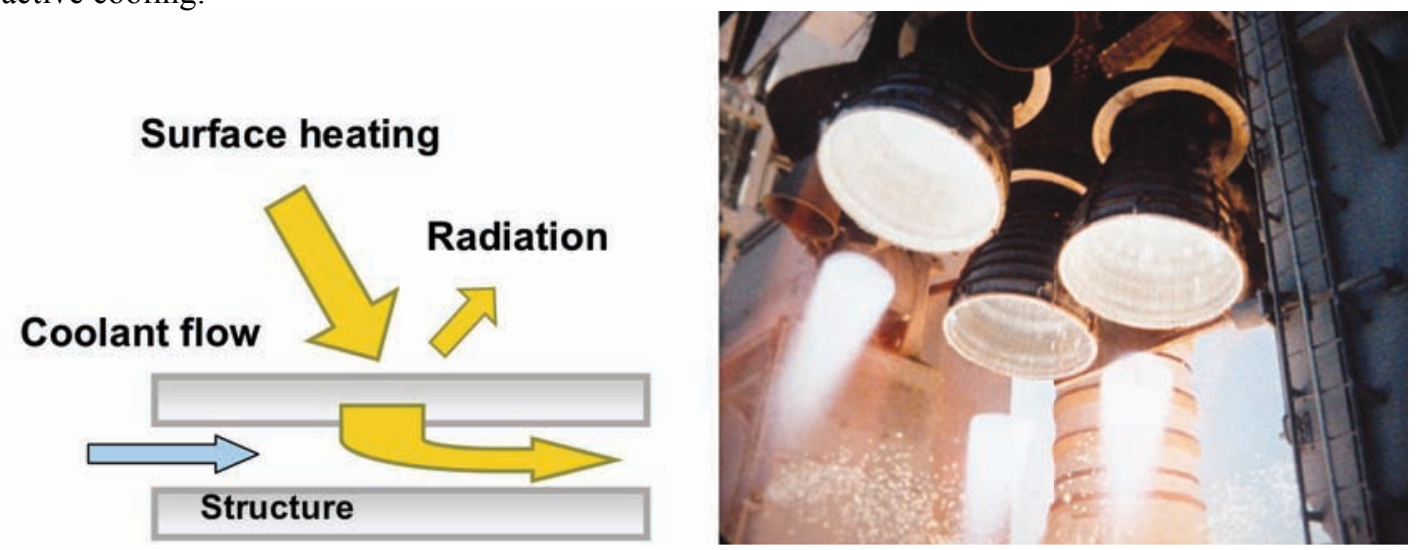

Figure 9. Schematic and photograph of actively cooled structure (SSME).

Film cooling, used inside a propulsion system, is another approach used for high heat fluxes for long times. For film cooling, the coolant is injected into the flow, usually at an upstream location and at a single, discreet, location (Figure 10). It operates as a thin, cool, insulating blanket. The structure will reach high temperatures and operate hot.
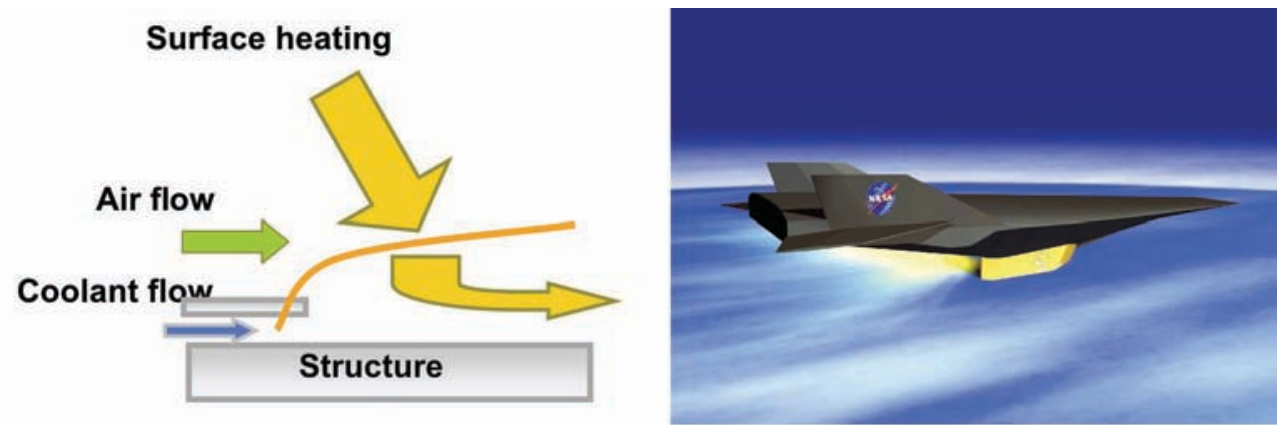

Figure 10. Schematic of film cooling and drawing of a hypersonic vehicle.

Transpiration cooling is the final active cooling approach. This cooling method is used for high heat fluxes and long times. An example in Figure 11 shows a cooled carbon/carbon $(\mathrm{C} / \mathrm{C})$ combustion chamber test article. 
For transpiration cooling, the coolant is injected into the hot gas flow through a porous structure continuously over large areas as opposed to a discrete location with film cooling. The coolant also decreases the heat flux to the structure and, again, the structure operates hot.
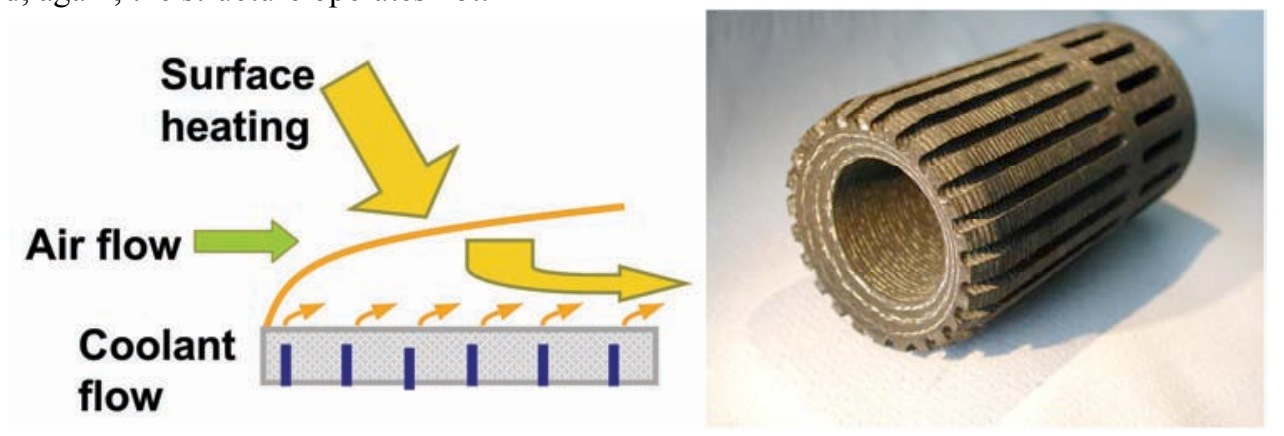

Figure 11. Schematic of transpiration cooling and a $\mathrm{C} / \mathrm{C}$ cooled combustion chamber test article [1].

Different thermal management techniques are applied to different flight vehicles. Figure 12 shows the temperature versus exposure time for multiple vehicles. Shown in the top left of Figure 12 are re-entry capsules Apollo/CEV (Orion) and Mercury, which all use(d) ablators due to very high temperatures, but relatively short times. The X-15 used a heat sink approach, due to short times and relatively moderate temperatures. The SR-71 experienced longer flight times resulting in a hot structure design and, again, the temperatures were moderate. The Space Shuttle Orbiter is an insulated aluminum airframe with moderate temperatures and exposed for longer times. Moving forward with air-breathing hypersonic vehicles, as illustrated by an SSTO vehicle, a new approach will be needed to thermally protect the vehicles. The new approach will inevitably encompass a wide range of different approaches, including hot structures, insulation, and active cooling.

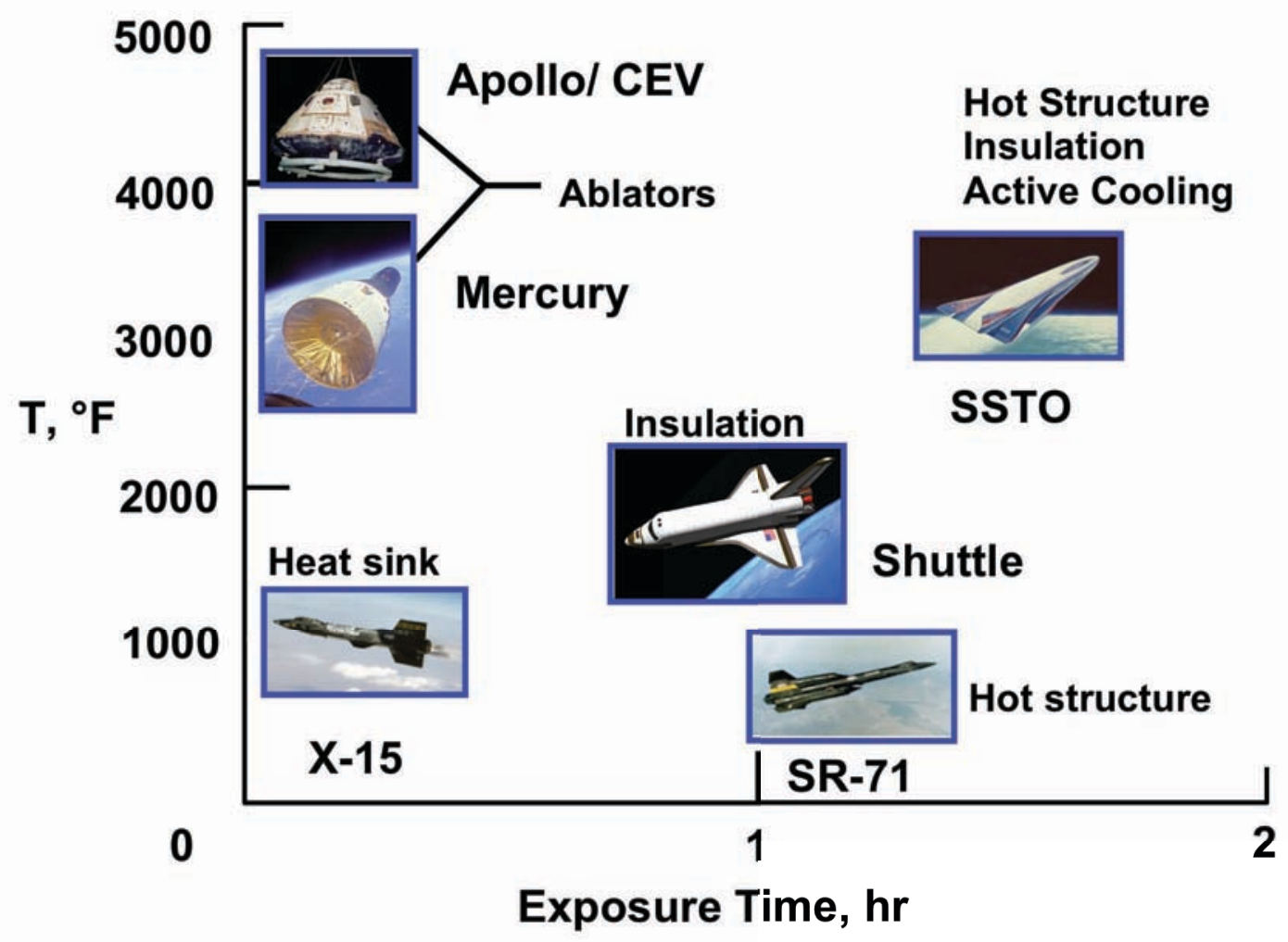

Figure 12. Thermal management approach for several vehicles as a function of temperature and exposure time [2]. 


\section{B. Thermal Protection Systems for Rocket-Launch Vehicles}

The Space Shuttle Orbiter, shown in Figure 13, utilizes a conventional, skin-stringer aluminum aircraft structure. The structural temperatures are required to stay below $350^{\circ} \mathrm{F}$ for re-use purposes. To keep the temperatures down to $350^{\circ} \mathrm{F}$, re-usable surface insulation tiles are used primarily on the windward surface, and reuseable blankets are used primarily on the leeward surface. For the leading edges and the nose cap, where temperatures are greater than $2,300^{\circ} \mathrm{F}$, reinforced carbon/carbon $(\mathrm{RCC})$ is used.

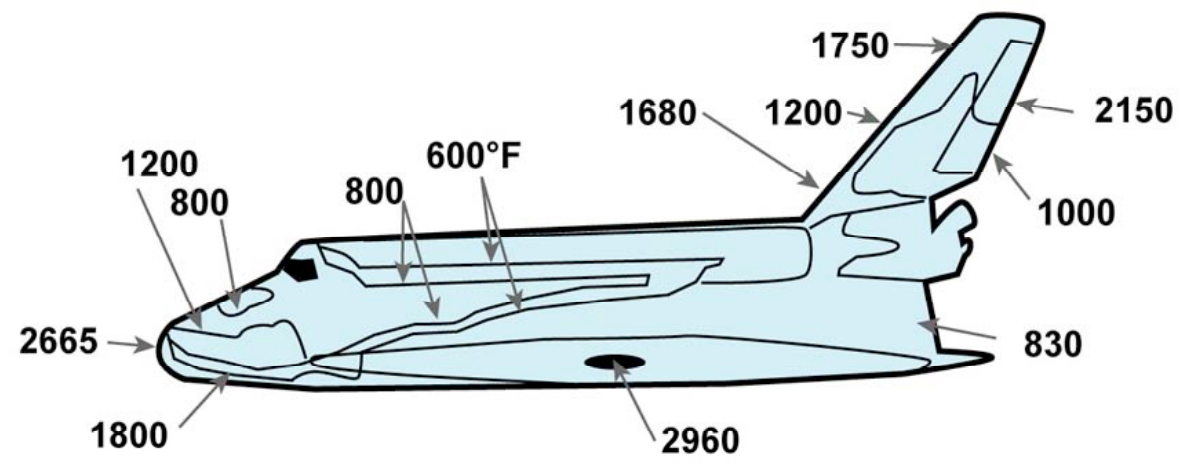

Figure 13. Nominal maximum temperatures on the surface of the Space Shuttle Orbiter [2].

The X-33 was a sub-orbital experimental vehicle that NASA funded (but canceled prior to flight) that was intended to be the predecessor for an SSTO rocket vehicle. The TPS on the X-33 was similar to the Space Shuttle Orbiter TPS, except that it had a metallic TPS on the windward surface. As shown in Figure 14, blankets were utilized on the leeward surface and metallic TPS was utilized on the windward surface of the X-33. Both vehicles utilize(d) carbon/carbon leading edges, nose cap, chin, and skirt.

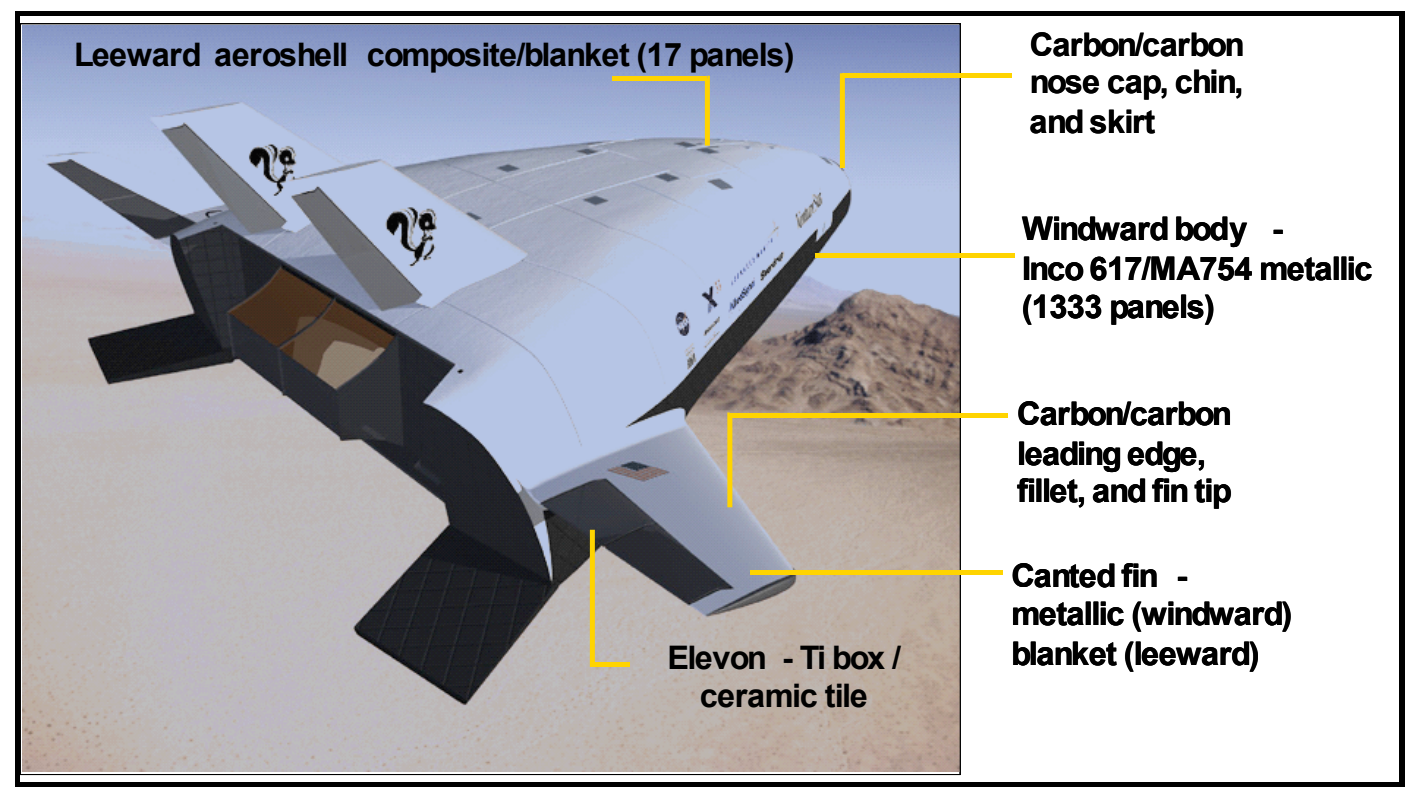

Figure 14. Thermal protection system utilized on the X-33.

\section{TPS and Hot Structures for Air-Breathing Hypersonic Vehicles}

For an air breathing vehicle, the aerothermodynamics, propulsion system, and airframe, including much of the TPS and hot structures, are highly integrated, as shown in Figure 15 where the entire under side of the vehicle is part of the propulsion system. This is very different from most rocket-based systems. The differences between rocket-based and air-breathing vehicles have significant impacts on the airframe structures.

The differences in rockets and air-breathers (Figure 16) impacts how thermal management and TPS are handled. Rockets accelerate, but do not cruise, while in atmospheric flight, and are usually launched vertically. 
They leave the atmosphere quick ("up and out") and generally fly at a low dynamic pressure. Conversely, airbreathers accelerate and cruise in the atmosphere. They are often launched (or take off) horizontally and fly at a high dynamic pressure because they fly low in the atmosphere at high velocities to capture the air for the engine.

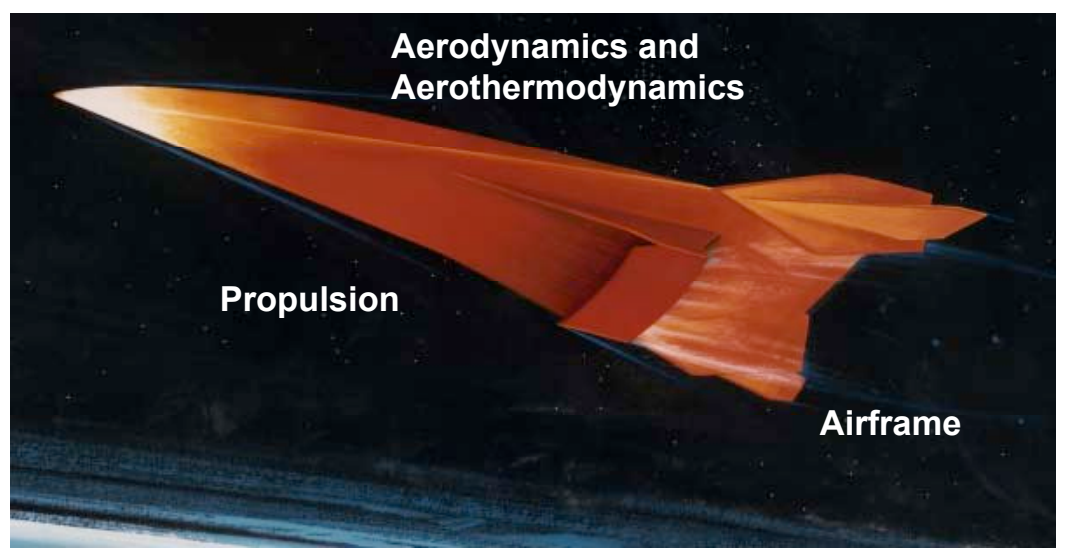

Figure 15. Schematic of a hypersonic vehicle illustrating the interaction of the aerothermodynamics, propulsion, and airframe.

For rocket-based vehicles (such as the Space Shuttle Orbiter), high drag is not a problem on ascent and high drag is desired on descent for deceleration. Air- breathers, on the other hand, are optimized for low drag and thus have thin, slender bodies with low thickness to chord ratio.
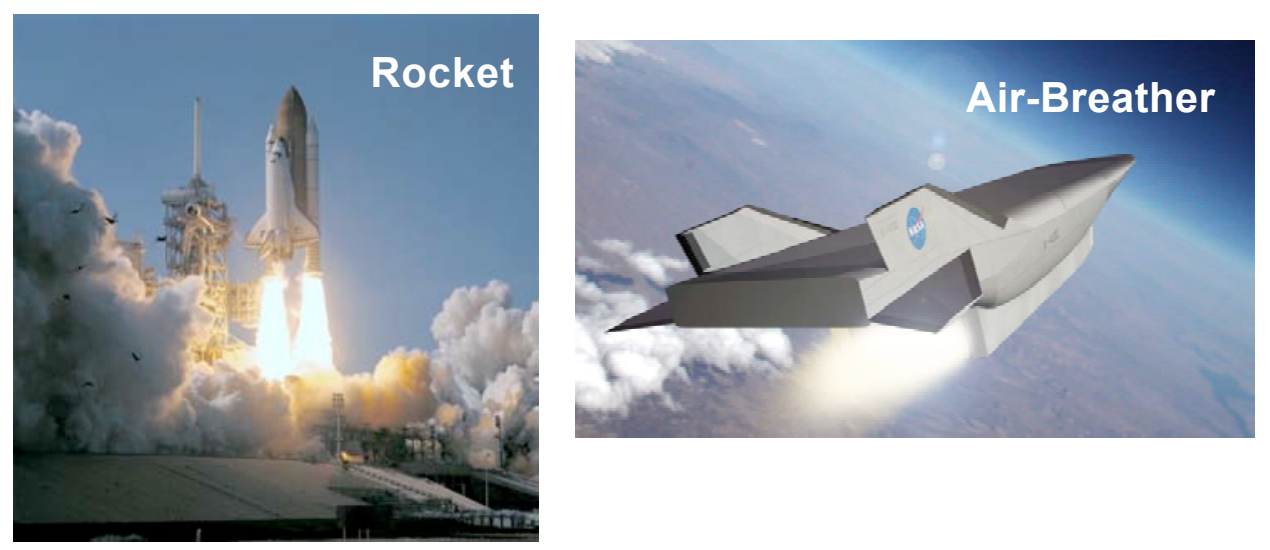

Figure 16. Typical rocket and air-breathing vehicles.
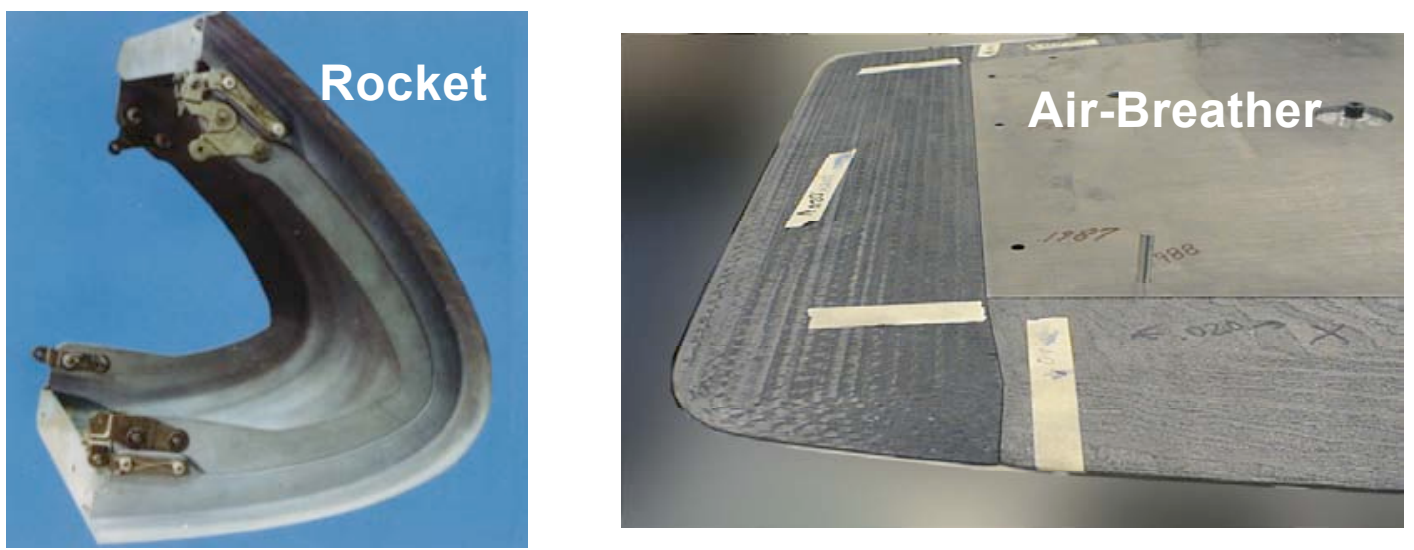

Figure 17. Blunt leading edges typical of a rocket based vehicle (Space Shuttle Orbiter) versus the sharp leading edges on the $\mathrm{X}-43$. 
Weight and volume are another difference between rockets and air-breathers. Rockets are extremely weight sensitive and the structural mass fraction is on the order of $10 \%$ of the gross take off weight (GTOW). This means that if there is 1 pound of structure added to a rocket-based vehicle, then 10 pounds of weight will be added to the total system. Air-breathers tend to be more volume sensitive, which impacts the drag. The structural mass fraction is in the range of $30 \%$ of the GTOW. Weight is also extremely important for air breathers, but the volume is what drives the drag.

The difference in trajectories impacts the TPS. Rockets are driven by high descent heating. Ascent heat loads are generally low due to the short ascent time and the "up and out" trajectory. Air-breathers are driven by ascent, descent, and cruise, and are exposed to high heat loads due to their long ascent times at high dynamic pressure.

On a rocket, leading edges tend to be blunt due to a desire for a high descent drag and low heat flux. Airbreathers have sharp leading edges due to the desire for low drag and low thickness to chord ratio. The heat fluxes are high because of the sharp radii (Figure 17) and high dynamic pressure.

\section{Thermal-Structural Challenges}

Thermal structural challenges can be quite severe on air-breathing vehicles. One of the primary thermalstructural challenges results from large thermal gradients. For example, in a cryogenic tank containing liquid hydrogen as a fuel, the liquid hydrogen will be $-423^{\circ} \mathrm{F}$ and the outer surface of the TPS may be between $2,000^{\circ} \mathrm{F}$ and $3,000^{\circ} \mathrm{F}$. With different materials operating at a wide range of temperatures, attaching the various components (tank, insulation, structure, TPS, etc.) that are growing and shrinking at different magnitudes is challenging. Control surfaces are often hot and are often connected to an actuator inside the vehicle which is much cooler. On some structures, there are thin cross-sections (due to the need for low drag) at high mechanical loads. These high mechanical loads are often imposed at elevated temperatures. The stability of the outer mold line is important since it can impact performance. For example, sharp nose leading edges generate shocks which are necessary to maximize airflow into the engines. As a result, leading edges should not ablate, both to generate the desired shocks, and to enable re-use. Steps and gaps can be a problem. Gaps may potentially allow sneak flow, where hot plasma leaks into the structure. Forward facing steps may result in local hot spots, thus locally increasing the surface temperature. Thermal expansion of the propulsion system creates other issues. On airbreathers, the propulsion system includes much of the under surface of the vehicle, is very long, and can grow several inches. It must be attached to the airframe and allow for the differential growth between the propulsion system and the airframe. Other vehicle and structural challenges include affordability. Production costs, life cycle cost, and inspection and maintenance costs are all important. Other issues to consider are damage tolerance, low speed impact such as tool drop, foreign object damage on a runway, hyper-velocity impact, weather, and reuse potential.

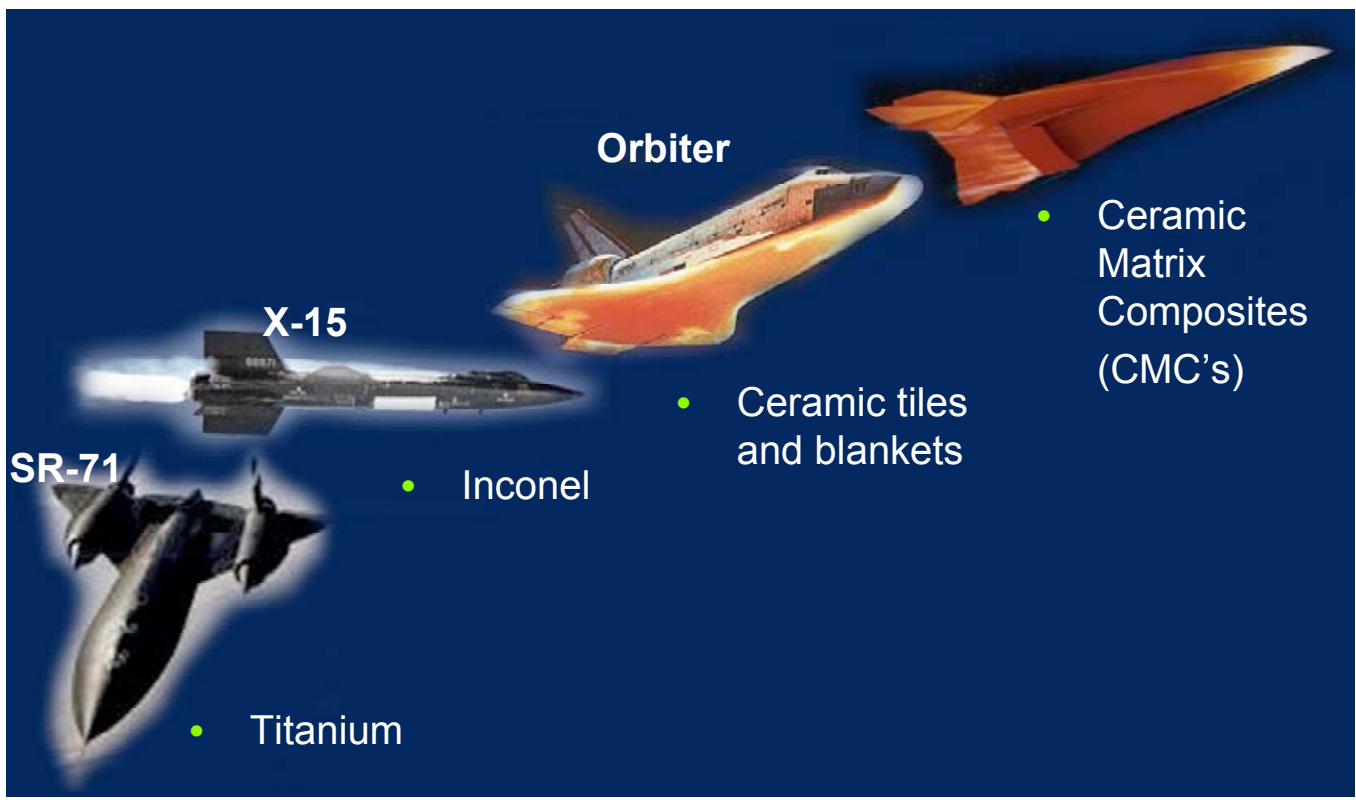

Figure 18. Examples of where new material systems have helped enable new vehicles. 
All of these requirements lead to a new approach to thermal protection and move us away from the Shuttle Orbiter type of insulated airframe. History shows the use of new material systems enable vehicles. Figure 18 illustrates the SR-71 where titanium was used. The manufacturing processes and databases had to be extended to higher temperatures to enable its use. The same is true for the X-15 with Inconel, where manufacturing processes and databases had to be extended to higher temperatures to enable its use. The Space Shuttle Orbiter is an aluminum "airplane" with ceramic tiles and blankets, which were developed to enable this type of vehicle to be flown.

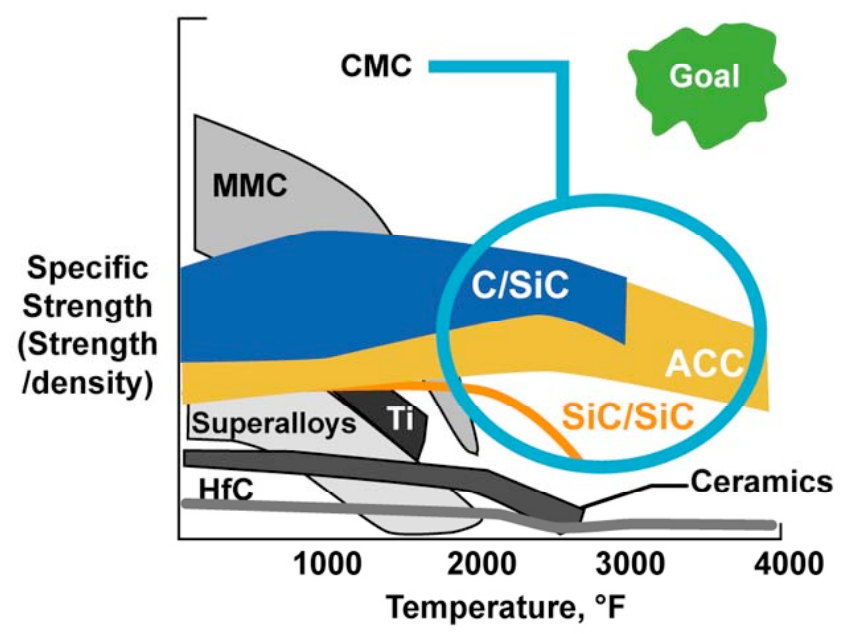

Figure 19. Material specific strength as a function of temperature for several material classes.

The required material attributes for hypersonic air-breathing vehicles are high temperature capability (2000 to $4000^{\circ} \mathrm{F}$ ), high strength at those elevated temperatures, high toughness, light weight, and environmental durability. Figure 19 shows material specific strength, which is strength divided by density, versus temperature. High specific strength at elevated temperature is the goal, which is obtained with high strength and low density, and is shown in the shaded region in the top right hand corner. Metallic options include metallic matrix composites (MMC), super alloys, and titanium. These all have good specific strength, but it drops off by the $2000^{\circ} \mathrm{F}$ range. Grouped together as ceramic matrix composites (CMC), the $\mathrm{C} / \mathrm{SiC}$ material, advanced carbon/carbon (ACC), and $\mathrm{SiC} / \mathrm{SiC}$ provide high strength at elevated temperatures which are key for air-breathing vehicles.

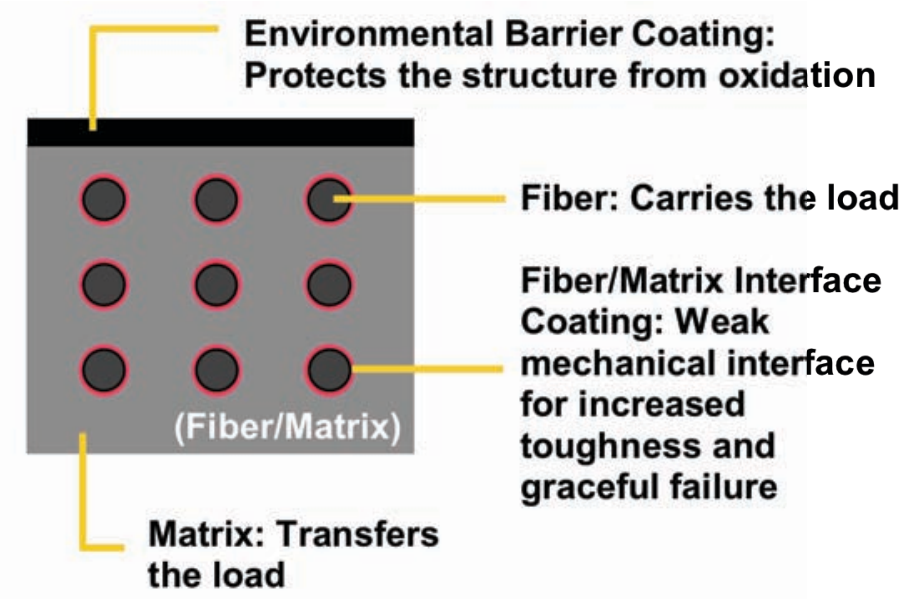

Figure 20. Schematic of a ceramic matrix composite with fibers inside of a matrix.

A CMC is illustrated in Figure 20, where fibers inside of a matrix are evident. The fibers carry the load and the matrix transfers the external load to the fibers. Depending on the processing and fabrication approaches, the fiber/matrix interface could have an interface coating which, if present, is the key to the toughness of the structure. 
It provides a weak mechanical interface for increased toughness and graceful failure. One of the key components of the $\mathrm{CMC}$ is the environmental barrier coating which protects the materials from oxidation at high temperatures.

\section{TPS and Hot Structures Components}

As discussed previously, much of the outer surface of hypersonic vehicles is subjected to severe aerodynamic heating. As a result, the airframe must be either protected from the heat, or designed to operate even when exposed to the extreme heating. The airframe components discussed here include leading edges, acreage TPS and aeroshells, and control surfaces.

\section{A. Leading-Edges}

Figure 21 shows typical ascent leading-edge heat flux for an SSTO vehicle. The wing leading edge heat flux is $\sim 500 \mathrm{Btu} / \mathrm{ft}^{2}$-sec and the nose $\sim 5000 \mathrm{Btu} / \mathrm{ft}^{2}$-sec. The cowl leading edge maximum heat flux is $\sim 50,000 \mathrm{Btu} / \mathrm{ft}^{2}$ sec, due to a Type IV shock-shock interaction. In comparison, the Space Shuttle Orbiter wing leading edge maximum heat flux is $\sim 70 \mathrm{Btu} / \mathrm{ft}^{2}-\mathrm{sec}$ and the CEV heat shield maximum heat flux on Lunar direct return is expected to be $\sim 700 \mathrm{Btu} / \mathrm{ft}^{2}$-sec.

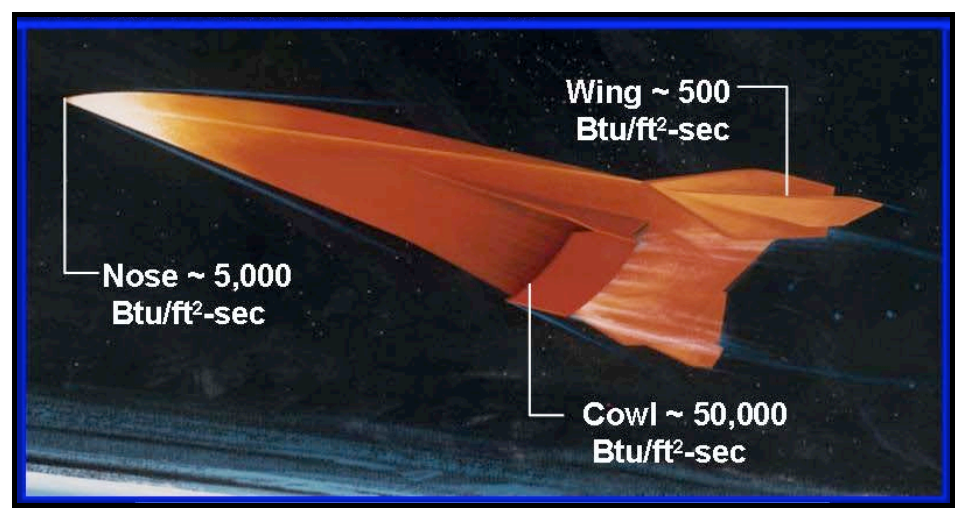

Figure 21. Typical ascent leading-edge heat flux for an SSTO vehicle.

The leading-edge radius has a significant impact on the heat flux. Heat flux is proportional to one over the square root of the radius. Figure 22 shows the heat flux as a function of radius, with a 1 -inch radius having a heat flux of $500 \mathrm{Btu} / \mathrm{ft}^{2}$-sec. As the radius increases, the heat flux drops. As the radius becomes smaller, which is required for most air-breathing vehicles, the heat flux increases significantly.

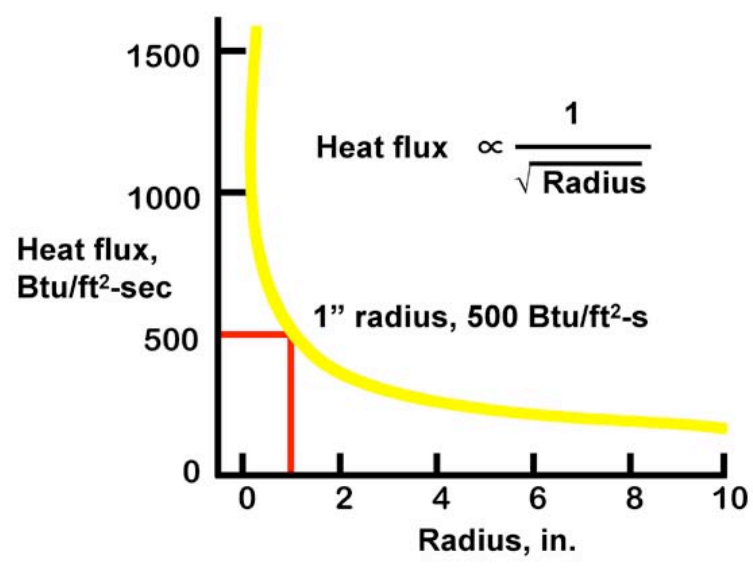

Figure 22. Effect of radius on heat flux.

Sharp leading edges impact the chordwise heat flux distribution in addition to the radius impacting the maximum value. The red area in Figure 23 shows the distribution around a sharp leading edge of a hypersonic 
vehicle. The stagnation line, indicated by the red arrow, would be basically at zero angle-of-attack. For a blunt leading edge, such as on the Space Shuttle Orbiter and shown in the light blue area, the heating distribution is more spread out around the leading edge. Also, for the Space Shuttle Orbiter distribution, the maximum heat flux (light blue arrow) is on the lower surface due to a high angle-of-attack. The net effect of the sharp leading edge is thus an intense, localized heating.

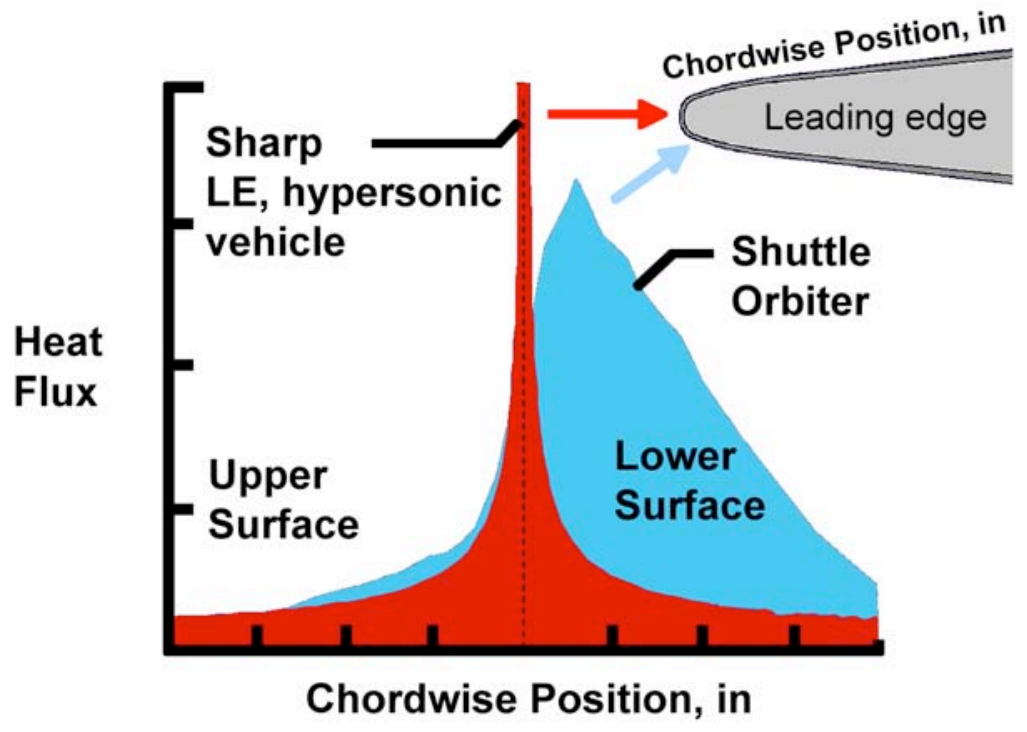

Figure 23. Effect of chordwise position on heat flux for a sharp and blunt leading edge.

For sharp leading edges, passive, semi-passive, and active thermal management options may be utilized to manage the intense localized heating. In Figure 24, for passive leading edges, there are re-use limits indicated by the horizontal line, below which the materials can be used for multiple missions. Above that temperature, the material becomes an ablator, and thus single use. The sequence of preferred options is passive, then heat-pipe or semi-passive, and then active. Active cooling results in increased costs, complexity, and weight, but is required for high heat flux.

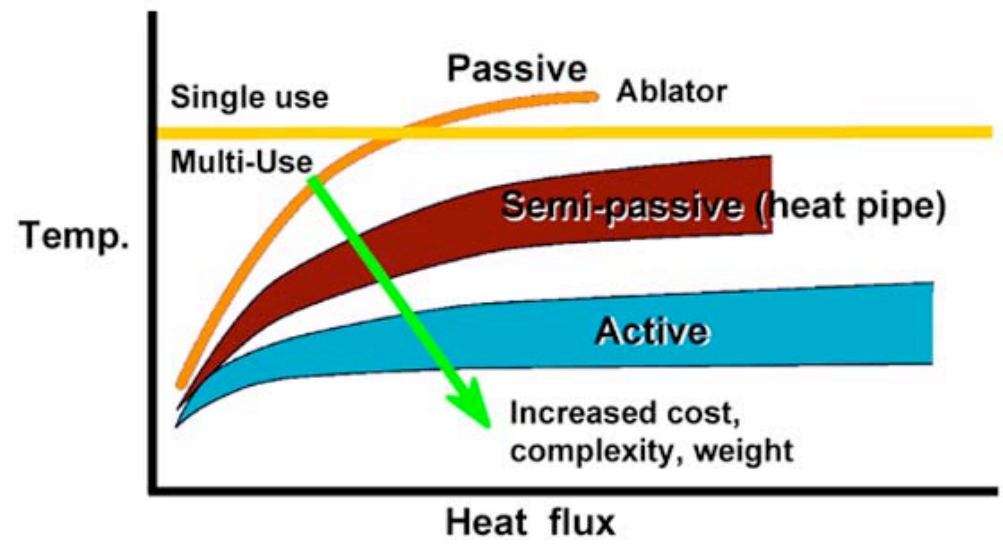

Figure 24. Leading-edge thermal management options.

\section{Passive Leading Edges}

Figure 25 illustrates the net energy flow on passive leading edges. There is a net heat input into the leading edge in the stagnation region. The heat is conducted aft of the stagnation region, where it is then radiated to space. The amount of heat transferred from the stagnation region aft is a function of the thermal conductivity of the leading edge material. The goal is to attempt both a) to have high-temperature materials to increase the 
capability of the leading edges and b) to manipulate the thermal properties to reduce the temperatures, resulting in temperatures below the re-use temperature of the leading edge.

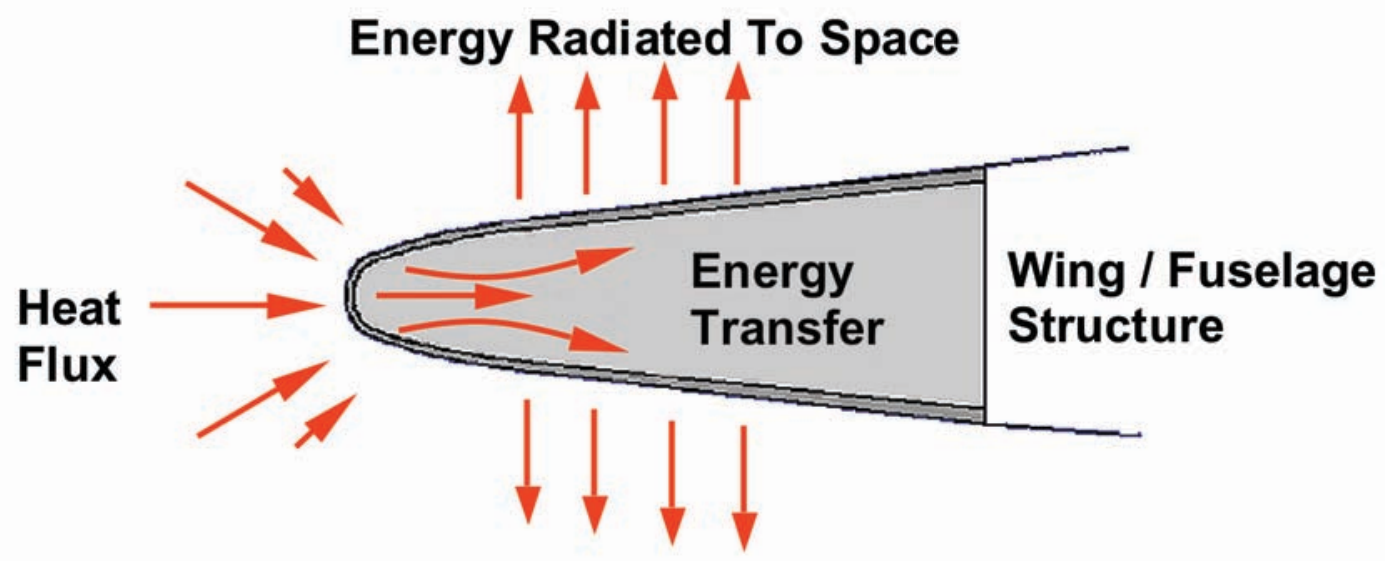

Figure 25. Net energy flow on passive leading edges.

High-Temperature Coatings

The SiC-based coatings such as used on the Space Shuttle Orbiter leading edges are good to $\sim 3000^{\circ} \mathrm{F}$. On air-breathing vehicles, there may be situations where the temperatures will be above $3000^{\circ} \mathrm{F}$, in which case a different class of materials will be required (e.g., carbides, oxides, and diborides of $\mathrm{Hf}$ and $\mathrm{Zr}$, etc.). These materials, such as $\mathrm{Hf}$ and $\mathrm{Zr}$, could be used as part of a composite matrix. Some materials, such as Ir, are more appropriate as a coating, as shown in Figure 26.

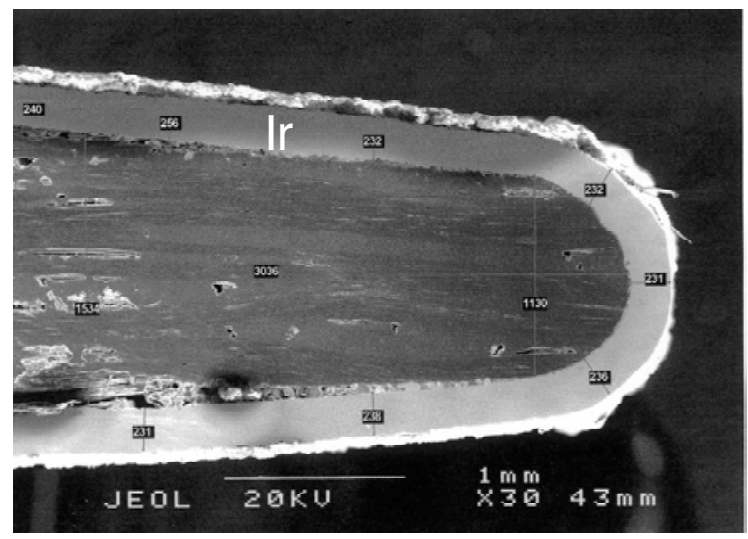

Figure 26. Photomicrograph of a cross-section of a $\mathrm{C} / \mathrm{C}$ leading edge with an iridium (Ir) coating.

Thermal Conductivity

The thermal properties of the material can also have a significant impact on the surface temperatures. One such thermal property is the thermal conductivity of the fiber and the weave architecture. There are multiple grades of carbon fiber with different thermal conductivity. The fibers can also be woven with different architectures. High thermal conductivity fibers in an unbalanced weave help spread heat, avoid hot spots, and survive high heat flux environments. Figure 27 illustrates $3: 1,4: 1$, and 5:1 plain weaves. In the 3:1 $(75 / 25$ unbalanced) plain weave, there are three times as many fibers in the " 3 " direction as in the " 1 " direction.

For the 3:1 plain weave, the thermal conductivity is $190 \mathrm{Btu} / \mathrm{hr}-\mathrm{ft}-{ }^{\circ} \mathrm{F}$ in the " 3 " direction and $70 \mathrm{Btu} / \mathrm{hr}-\mathrm{ft}-{ }^{\circ} \mathrm{F}$ in the " 1 " direction. The 4:1 and the 5:1 plain weaves show the thermal conductivity increasing in the strong (or primary) direction, and decreasing in the weak direction. These leading edges with the 3:1, 4:1, and 5:1 architecture were all arc-jet-tested. The 5:1 weave architecture was able to remove more heat from the leading edge than the 3:1 architecture, thus demonstrating a better thermal performance and survivability with the highly unbalanced architectures. It should also be pointed out that though the thermal performance is enhanced in the strong direction, the strength in the weak direction is reduced. 


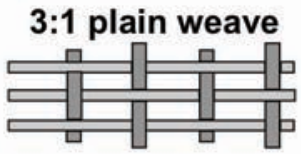

$\mathrm{k}_{3}=190 \mathrm{Btu} / \mathrm{hr}-\mathrm{ft}-{ }^{\circ} \mathrm{F}$

$\mathrm{k}_{1}=70 \mathrm{Btu} / \mathrm{hr}-\mathrm{ft}-{ }^{\circ} \mathrm{F}$

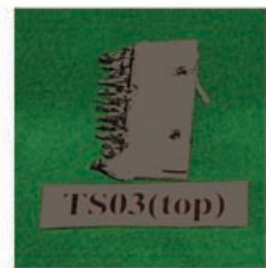

4:1 plain weave

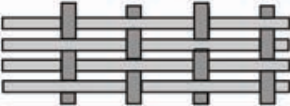

$\mathrm{k}_{4}=200 \mathrm{Btu} / \mathrm{hr}-\mathrm{ft}-{ }^{\circ} \mathrm{F}$
$\mathrm{k}_{1}=60 \mathrm{Btu} / \mathrm{hr}-\mathrm{ft}-{ }^{\circ} \mathrm{F}$

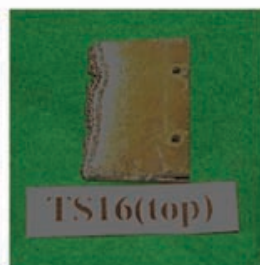

5:1 plain weave

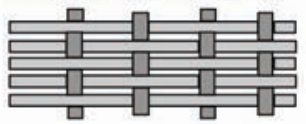

$\mathrm{k}_{5}=210 \mathrm{Btu} / \mathrm{hr}-\mathrm{ft}^{\circ} \mathrm{F}$

$\mathrm{k}_{1}=50 \mathrm{Btu} / \mathrm{hr}-\mathrm{ft} /{ }^{\circ} \mathrm{F}$

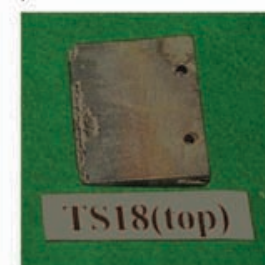

Figure 27. Illustration of 3:1, 4:1, and 5:1 plain weaves, respective nominal thermal conductivities, and photographs of arc-jet tested leading edges.

\section{Emissivity}

Emissivity is another important parameter that affects the surface temperatures. The radiation equilibrium temperature, shown in Figure 28, is a function of the surface heat flux and the emissivity. The figure illustrates a radiation equilibrium condition, where the convective heat flux equals the heat that is radiated away from the surface. As an example, if the incoming convective heat flux and the radiated heat flux are $\sim 50 \mathrm{Btu} / \mathrm{ft}^{2}-\mathrm{sec}$, with an emissivity of 0.8 , the surface temperature will be $\sim 3000^{\circ} \mathrm{F}$. If the emissivity is lower, for example 0.3 , the surface temperature will increase to near $4000^{\circ} \mathrm{F}$ in order to radiate away the same $50 \mathrm{Btu} / \mathrm{ft}^{2}-\mathrm{sec}$.

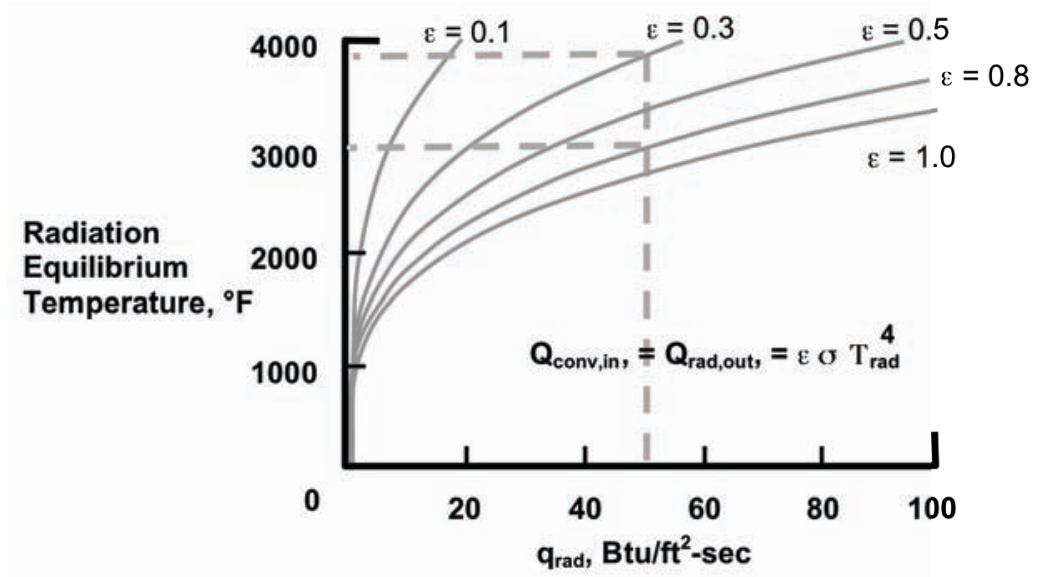

Figure 28. Effect of emissivity on radiation equilibrium temperature.

Recombination (Catalytic) Efficiency

The recombination (catalytic) efficiency is another important parameter. There are disassociated species in the hypersonic flow. For example, the air will be disassociated and there will be recombination of that flow. The surface will serve as a catalyst to increase the recombination. This recombination can be exothermic - meaning the reaction gives off heat. Heat will be released at the surface, thus providing heat to the surface. In addition to recombination of the gas flow, recombination of surface atoms can result in increase heat flux. Silicon gas released from the surface coating reacting with an oxygen atom to form $\mathrm{SiO}$ is an example of a reaction which is exothermic and releases $\sim 605 \mathrm{Btu} / \mathrm{mol}$.

$$
\mathrm{Si}_{(\mathrm{g})}+\mathrm{O} \leftarrow \rightarrow \mathrm{SiO}
$$

A plot of heat flux versus recombination efficiency is shown in Figure 29 [3]. The data represent an arc-jet test at Mach 4 with an emissivity of 0.84 , and shows how the recombination efficiency impacts the surface heat flux. When the recombination efficiency is close to zero, the surface is referred to as non-catalytic, and the heat 
flux is $\sim 10 \mathrm{Btu} / \mathrm{ft}^{2}$-sec. For a fully catalytic surface with a recombination efficiency of one, the heat flux is $\sim 28.3$ $\mathrm{Btu} / \mathrm{ft}^{2}$-sec. The catalycity of the surface resulted in nearly a factor of three increase in the surface heat flux.

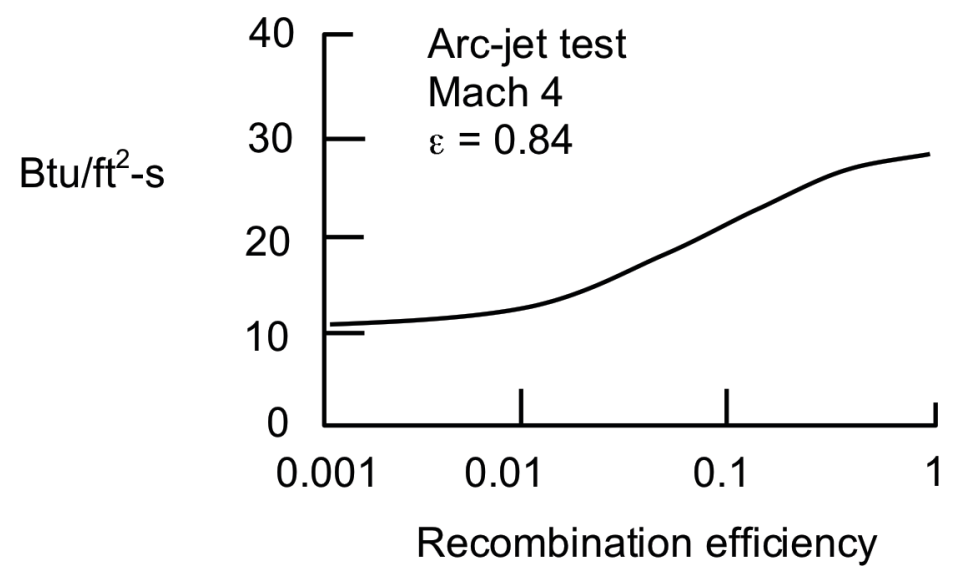

Figure 29. Plot of heat flux versus recombination (catalytic) efficiency from an arc-jet test [3].

Thermal Expansion

Another important property is the thermal expansion. As shown in the top row of Figure 30, a rod that is initially at a uniform temperature, $T_{0}$, and is heated up to a higher temperature $T_{1}$, will increase in length, $\Delta \mathrm{L}$. It is constrained at one end and free to grow on the other end. The strain, which is the growth $\Delta \mathrm{L}$ divided by the initial length, and the stress in that rod would be zero because it is allowed to grow. If the rod is constrained on both ends (assume one dimension) and heated to a higher temperature, the strain is zero because it is not growing. However, the stress in the rod is now non-zero. The stress is equal to the modulus of elasticity, E, times the thermal expansion, $\alpha$, times the temperature difference, $\Delta \mathrm{T}$.

The third row in the figure illustrates one of the main challenges in thermal structures, which results from a temperature gradient. In the third row of the figure (illustrating a two dimensional example versus one dimension in the first two rows), the growth is constrained in one direction, but there is also a temperature gradient across the rod in the other direction. The strain is non-zero because it is growing and the stress is non-zero. The thermal stress is generated due to a materials thermal expansion, a temperature differential, and a structural or mechanical restraint of the thermal growth. Thermal stresses can be difficult to address due to the fact that they differ from mechanical stresses in that with mechanical stresses, "beefing" up the structure can lower the stresses, while for thermal stresses, a thicker structure can actually increase the stresses.

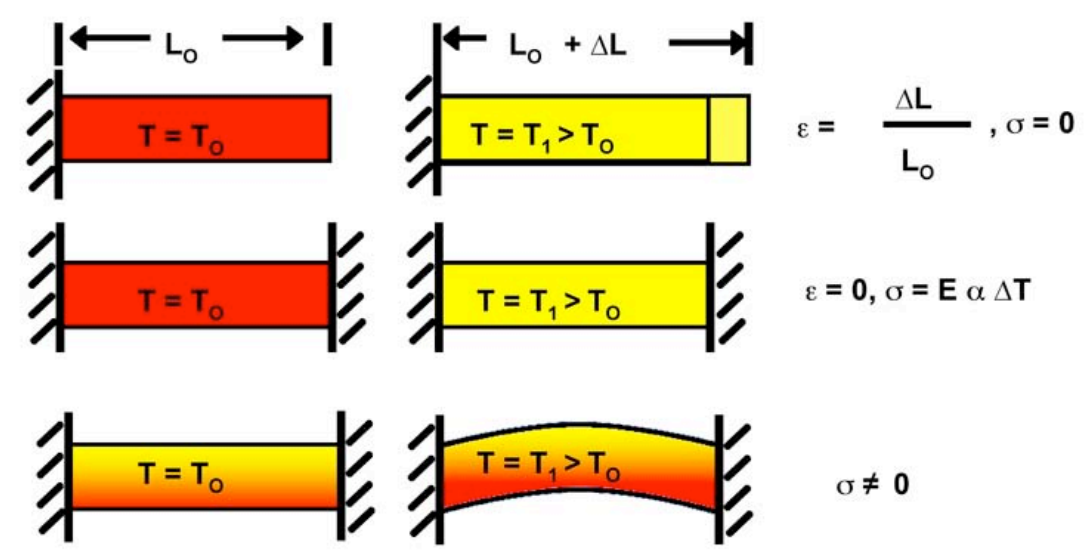

Figure 30. Impact of thermal expansion on stress and strain.

Oxidation

Oxidation is a key factor in high-temperature structures due to the long desired life times. To maximize the life of the structure, the goal is to operate in the passive oxidation regime. The first equation in Figure 31 shows 
silicon carbide as a solid, which is the coating material on many refractory composite structures. If there is high oxygen pressure, then there is plenty of oxygen. The silicon carbide reacts with two oxygen molecules to form silicon dioxide (silica), $\mathrm{SiO}_{2}$, which is a protective barrier for the structure. The silica is a solid and forms a protective scale on the surface. There is also emission of $\mathrm{CO}_{2}$ gas as a by product of the reaction.

$$
\begin{aligned}
& \text { Passive oxidation (high temperature and pressure) } \\
& -\mathrm{SiC}_{(\mathrm{s})}+2 \mathrm{O}_{2(\mathrm{~g})} \rightarrow \mathrm{SiO}_{2(\mathrm{~s})}+\mathrm{CO}_{2(\mathrm{~g})}
\end{aligned}
$$

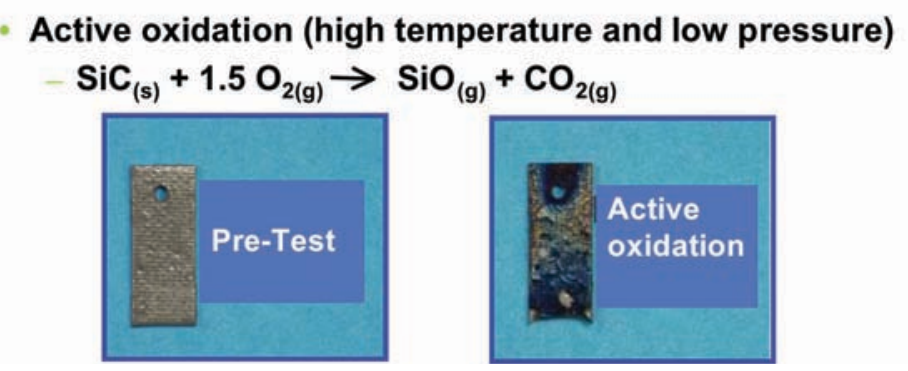

Figure 31. Comparison of active and passive oxidation.

If operating in a low pressure environment, active oxidation can occur at high temperatures. In a low pressure environment, there is not enough oxygen available, so for each silicon atom, only 1.5 oxygen atoms are available (versus 2 in a high pressure environment). The result is the formation of $\mathrm{SiO}$, instead of the protective $\mathrm{SiO}_{2}$. The result is active oxidation. Since $\mathrm{SiO}$ is a volatile gas, it does not form a protective scale (as does the $\mathrm{SiO}_{2}$ ). The silicon carbide coating is attacked as $\mathrm{SiO}$ gas is formed and leaves the surface. The photographs in Figure 31 illustrate a pre-test specimen with a silicon carbide coating and the specimen after testing in an active oxidation environment. The transition between the passive and active oxidation regime depends on the temperature and the oxygen partial pressure.

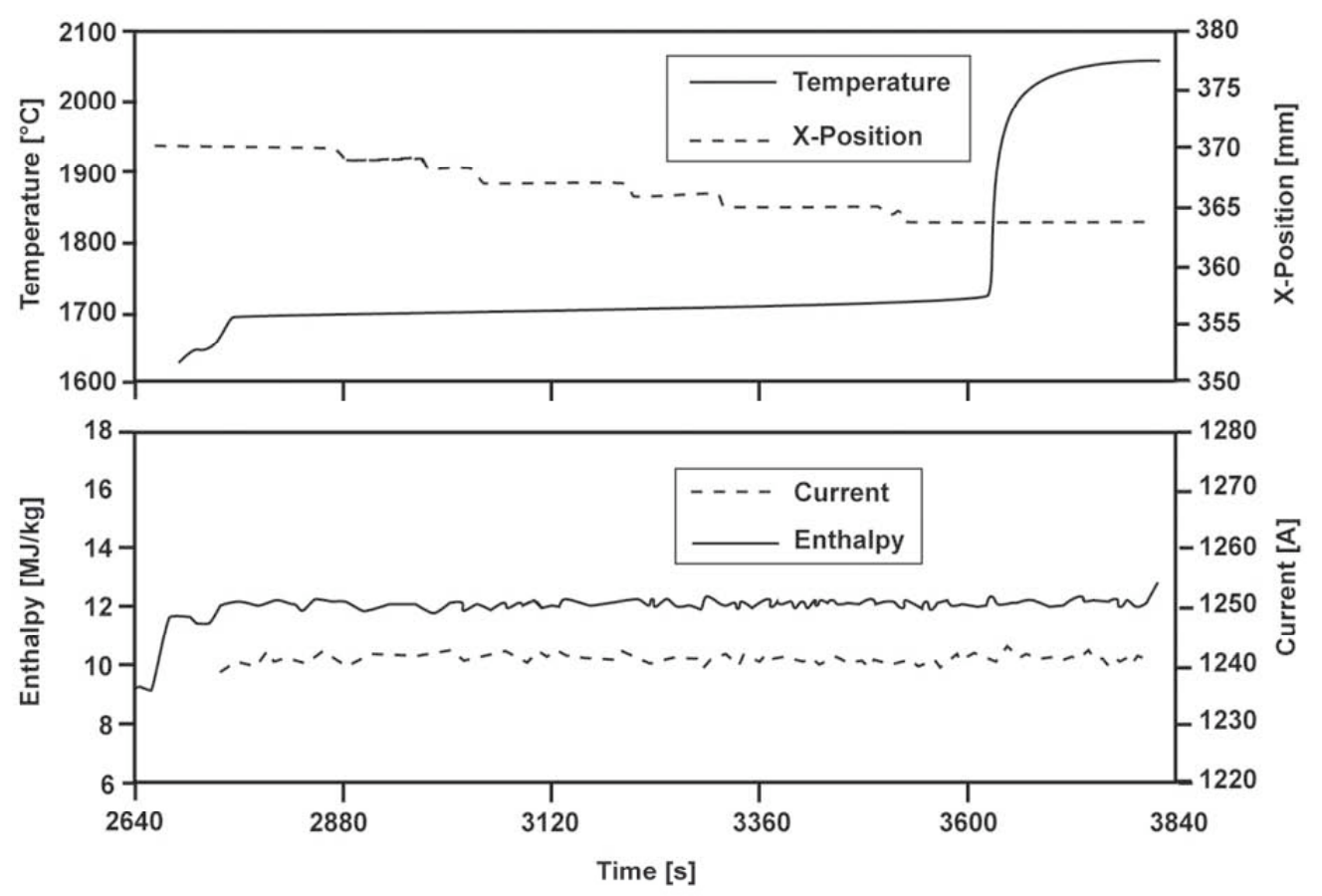

Figure 32. Temperature vs. time (top) and flow enthalpy vs. time (bottom) illustrating a large temperature rise at the passive to active oxidation interface [4]. 
The top graph in Figure 32 shows the temperature versus time and position versus time for a specimen in an arc-jet environment [4]. As the specimen is gradually moved closer to the nozzle (x-position decreasing), the temperature gradually increases. Once the temperature and pressure cross over into the active oxidation regime, there is a significant jump in the surface temperature. This effect has been noticed at multiple temperature/pressure combinations. The lower plot shows that the flow field energy remained relative constant during the test.

\section{X-43 Leading Edge}

As an example of a passive leading-edge design approach, consider the X-43 Mach 10 vehicle nose leading edge, which was designed to reach nearly $4000^{\circ} \mathrm{F}$ during the short 130 -sec flight [5].

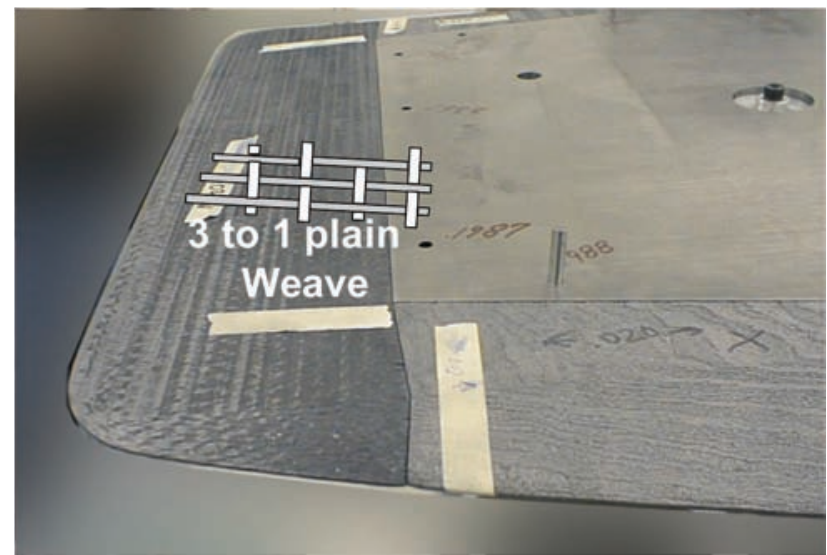

Figure 33. Photograph of $X-43$ leading edge with superimposed schematic drawing showing the 3:1 weave architecture of $\mathrm{C} / \mathrm{C}$ leading edge.

As described previously, high conductivity fibers can be woven into an unbalanced architecture to help conduct heat away from a leading edge, thus reducing the maximum temperatures. This approach was utilized on the X-43 Mach 10 vehicle, where a 3:1 (75/25 unbalanced) plain weave was used to obtain a high thermal conductivity in the chordwise direction, as shown in Figure 33.
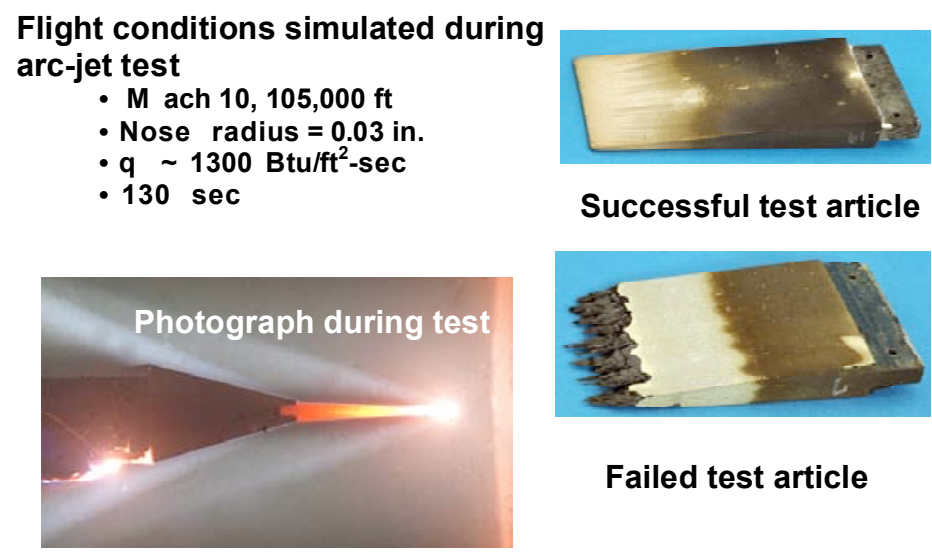

Failed test article

Figure 34. Arc-jet coating evaluation of X-43 leading edges.

For the X-43, the other approach to dealing with the high heat flux was to utilize high-temperature material systems. Thirteen different high-temperature materials were evaluated in an effort to find one that would survive the flight [5]. The flight conditions (Mach 10 at 105,000 feet) were simulated in the H2 arc-jet facility at Arnold Engineering and Development Center, Tullahoma, TN. The nose radius for the arc-jet test was 0.03 inches. The heat flux for the test was $1,300 \mathrm{Btu} / \mathrm{ft}^{2}$-sec, for about 130 seconds. The photograph on the bottom left in Figure 34 
shows a leading-edge test article during arc-jet testing. The figure also shows a successfully tested specimen and one that failed, where the coating came off and there was severe oxidization of the carbon/carbon substrate.

High thermal gradients can result in high thermal stresses, as was the situation on the leading edges of the Hyper X Mach 10 vehicle. The light green area in Figure 35 illustrates the original geometry and the dark green area illustrates a deformed geometry due to the thermal expansion resulting from the high temperatures. Thermalstructural modeling predicted the leading edges would fail due to the high compressive thermal stresses resulting from the constraint of the thermal expansion.

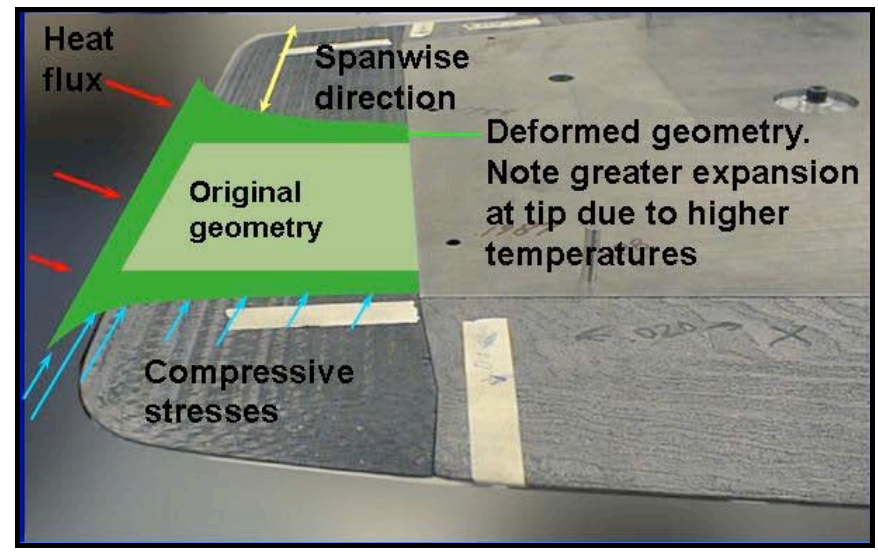

Figure 35. Illustration of spanwise compressive thermal stresses on the X-43 leading edge.

The predicted high thermal stresses raised several questions that needed to be answered prior to committing to flight. These questions included:

- Would the substrate, with coating, fail due to these high thermal stresses?

- Would the coating buckle and spall?

- Would the coating fall off, resulting in oxidation of the substrate?

- Would slotting be required to keep the leading edge from buckling? And, if so, what kind of spacing would be needed and would the slotting prevent spalling of the coating?

A series of tests at different scales confirmed that the leading edges would survive. [5]

\section{Shuttle Orbiter Wing Leading Edge Repair}

After the Space Shuttle Columbia accident, the Columbia Accident Investigation Board recommended that a wing-leading-edge repair capability be developed. Both a crack filler material and plug repair capability were developed and flew on the return to flight mission. The plug repair consists of several different 7-in-diameter $\mathrm{C} / \mathrm{SiC}$ cover plates attached to the RCC leading edges via a TZM refractory metal attach mechanism (Figure 36). A high temperature oxidation barrier was developed to protect the $\mathrm{C} / \mathrm{SiC}$ during the reentry. The $\mathrm{C} / \mathrm{SiC}$ cover plates were designed to maintain flexibility to reduce the number of plates taken to orbit (Figure 36). In addition, the protuberance was minimized to prevent excessive aerodynamic heating. The plug repair was validated via arcjet testing and is currently stowed on board the International Space Station (ISS). [6]

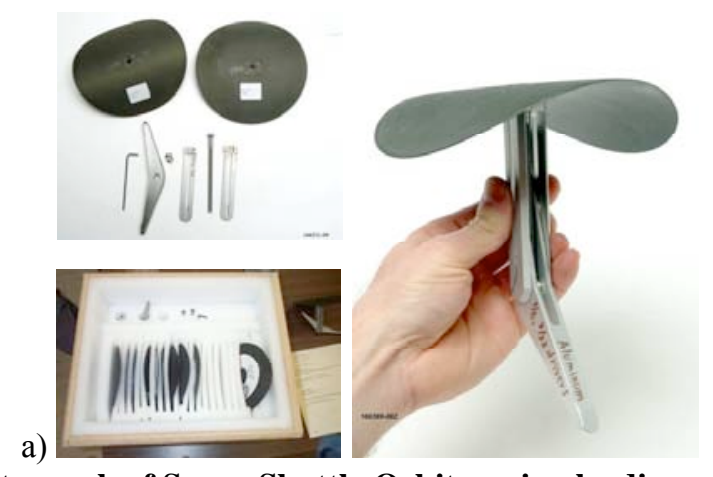

b)

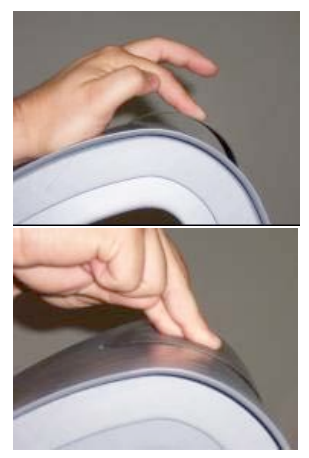

Figure 36. Photograph of Space Shuttle Orbiter wing leading edge plug repair a) $\mathrm{C} / \mathrm{SiC}$ cover plates and TZM attachment mechanism, and b) $\mathrm{C} / \mathrm{SiC}$ cover plate formed around simulated leading edge. 


\section{Heat-Pipe-Cooled Leading Edges}

When heat fluxes result in temperatures above the multi-use temperature of structures, other approaches need to be evaluated. Heat-pipe-cooled leading edges, which are semi-passive, utilize heat pipes to reduce leadingedge temperatures below the re-use limits of the materials.

A heat pipe is a self-contained, two-phase heat transfer device which is composed of a container, a wick, and a working fluid. A schematic diagram illustrating the operation of a heat pipe is shown in Figure 37 . Heat input locally to one section of the heat pipe, the evaporator region, is conducted through the container and into the wick/working-fluid matrix, where it is absorbed by the evaporation of the working fluid. The heated vapor flows to a slightly cooler section of the heat pipe where the working fluid condenses and gives up its stored heat. The heat is then conducted through the wick/working-fluid matrix and container and is rejected. The location of the heat pipe where heat is rejected is called the condenser region. The cycle is completed with the return flow of liquid condensate back to the heated region (evaporator) by the capillary pumping action of the wick. During normal operation, heat pipes operate as devices of very high effective thermal conductance and maintain a nearly uniform temperature over the entire heat-pipe length.

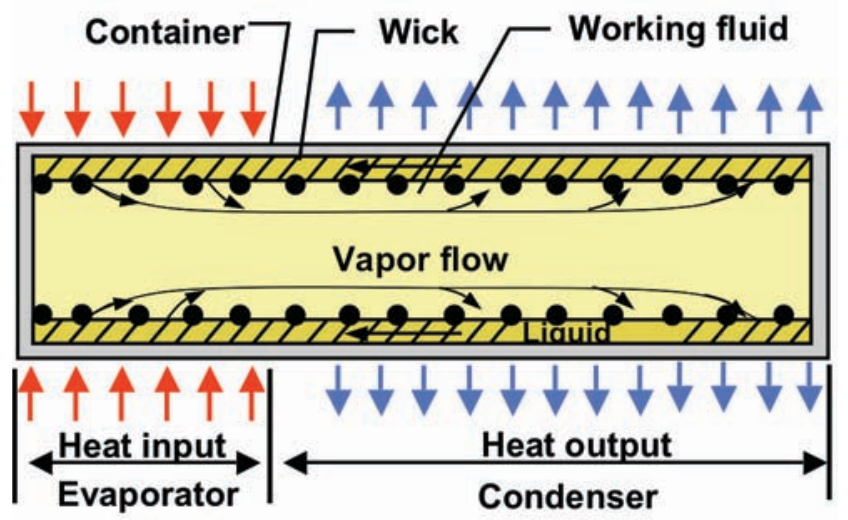

Figure 37. Schematic diagram illustrating the operation of a heat pipe.

Heat pipes provide cooling of stagnation regions by transferring heat nearly isothermally to locations aft of the stagnation region, thus raising the temperature aft of the stagnation region above the local radiation equilibrium temperature. When applied to leading-edge cooling, heat pipes operate by accepting heat at a high rate over a small area near the stagnation region and radiating it at a lower rate over a larger surface area, as shown in Figure 38. The arrows in Figure 38 indicate the net heat flux. The use of heat pipes results in a nearly isothermal leading-edge surface, thus reducing the temperatures in the stagnation region and raising the temperatures of both the upper and lower aft surfaces.

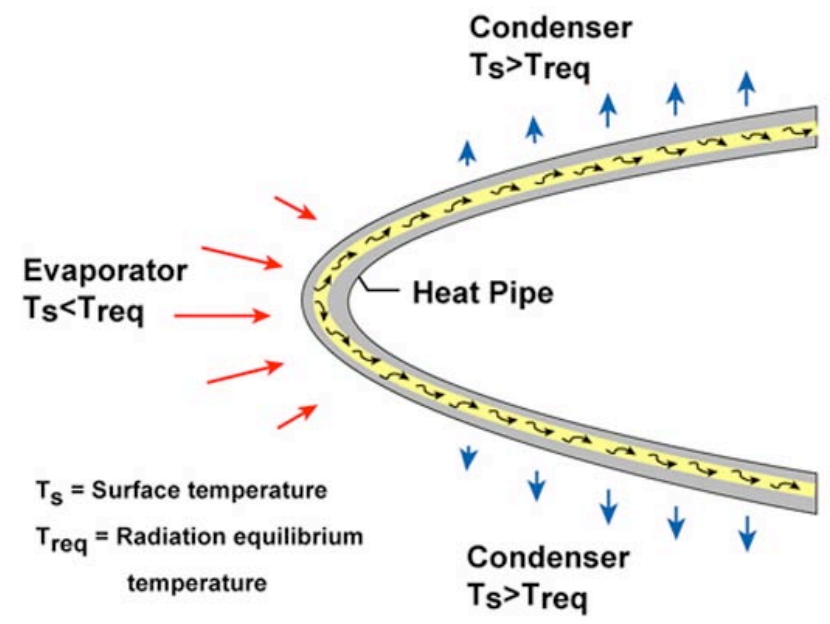

Figure 38. Leading-edge heat-pipe operation. 


\section{NASP Heat-Pipe-Cooled Wing Leading Edge}

Heat-pipe-cooled wing leading edges were studied during the National Aerospace Plane (NASP) program [7]. The leading edges had a carbon/carbon structure with Mo-Re heat pipes as the container, shown in Figure 39. Three straight Mo-Re heat pipes, $\sim 30$-in. long, were fabricated and embedded in carbon/carbon [8]. The heat pipes had a D-shaped cross-section and utilized Li as the working fluid.

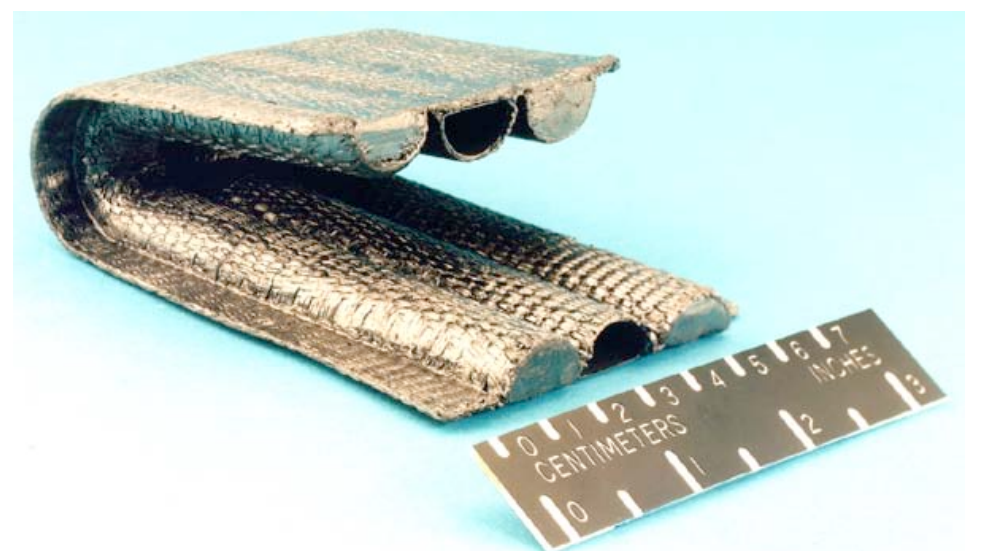

Figure 39. Photograph of Mo-Re tube embedded in C/C illustrating the design of a NASP heat-pipe-cooled wing leading edge.

A single leading-edge-shaped heat pipe was later fabricated and tested. Figure 40 shows a heat pipe in the shape of a leading edge that was fabricated for an advanced space transportation system [9]. Figure 41 shows how this particular heat pipe would fit and be utilized on a leading edge. This heat pipe utilized a Hastelloy-X container and sodium, a liquid metal, as the working fluid. The RF heating coils are evident at the nose region in Figure 40. The entire heat pipe is a uniform red color, indicating it is isothermal.

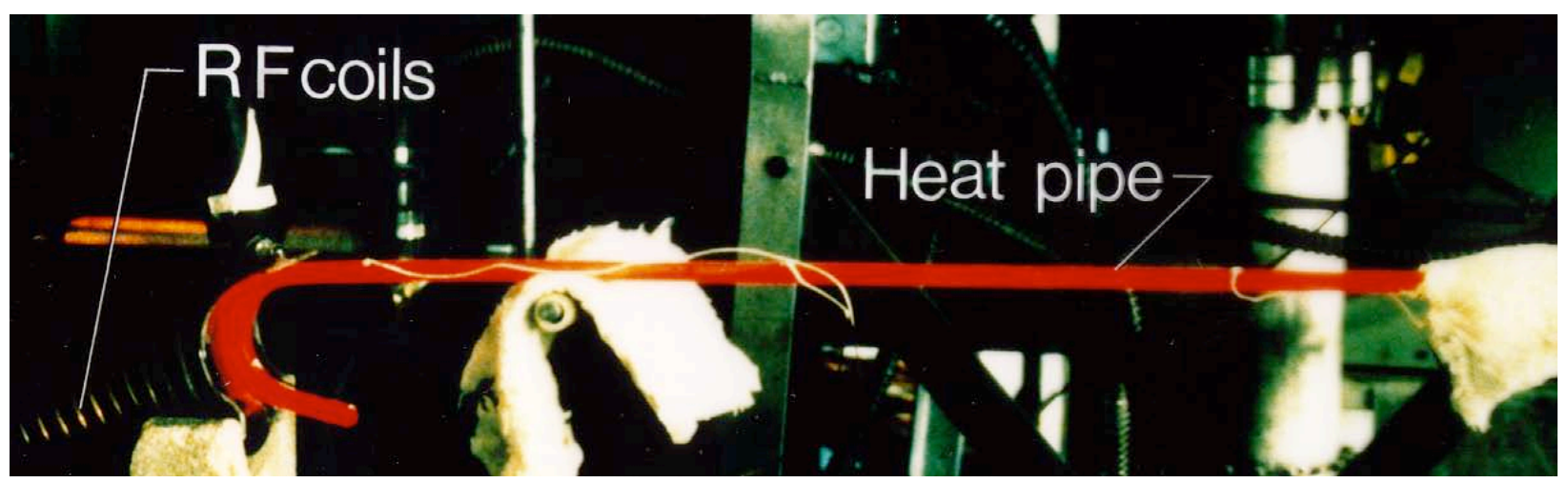

Figure 40. Leading-edge-shaped heat-pipe of uniform color illustrating constant heat pipe temperature.

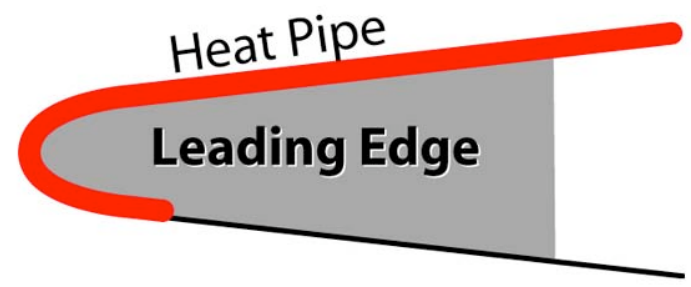

Figure 41. Schematic drawing showing placement of heat pipe on leading edge.

Material compatibility and thermal stresses are two of the major challenges with heat pipes embedded in composite materials such as carbon/carbon. Two different materials (carbon and Mo-Re for the container) at 
elevated temperatures for long durations are problematic. If the Mo-Re is in contact with the carbon/carbon, molycarbides will start to form. The formation of the molycarbides is a function of both time and temperature. Carbon may also diffuse through the Mo-Re into the heat pipe and degrade the heat pipe's operation. This diffusion is also a strong function of both time and temperature.

Thermal stresses present another problem. The Mo-Re has a larger coefficient of thermal expansion than $\mathrm{C} / \mathrm{C}$, and will thus be constrained by the $\mathrm{C} / \mathrm{C}$. Due to the constraint in growth, there is the possibility that the flat section of the heat pipe could buckle during operation. The difficulty here is that good thermal contact (throughthe-thickness) is required to transfer the heat from the outer surface into the heat pipe, but a loose fit is desired to minimize thermal stresses due to the mismatch in coefficient of thermal expansion.

\section{Actively-Cooled Leading Edges}

For the highest heat fluxes, active cooling is required. Metallic actively-cooled leading edges have been fabricated, and the challenges include hydrogen interaction and multi-cycle life. A photograph of the internal portion of an actively cooled leading edge is shown in Figure 42.

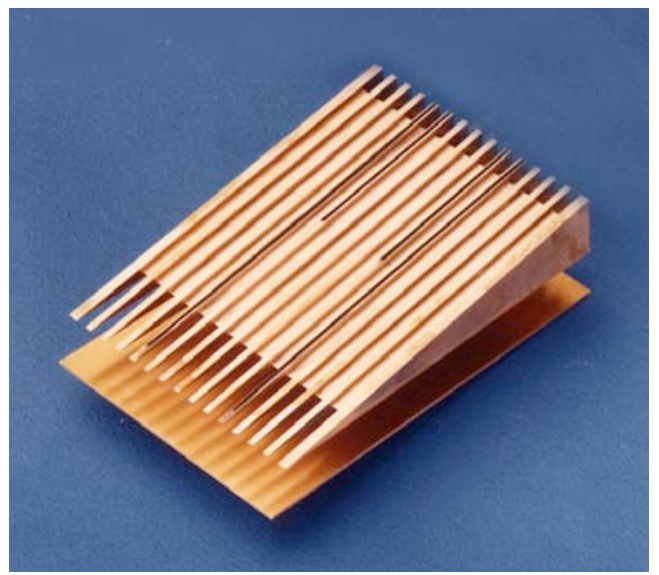

Figure 42. Photograph of the internal portion of an actively cooled leading edge.

With a goal of light weight and high-temperature capability, actively-cooled composites can provide significant benefits. As a first step, metallic tubes have been embedded in CMCs to hermetically seal the naturally porous CMCs. Materials that have been used to contain the coolant include superalloys and refractory metals. The concepts evaluated, shown in Figure 43, include: a composite with metallic tubes inserted to contain the coolant; co-processed metallic tubes in a composite; and braised tubes to obtain intimate contact with a composite.

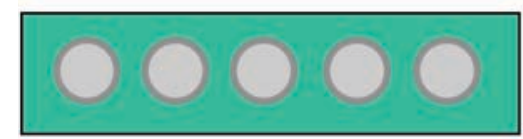

\section{Inserted metal tubes in composite}

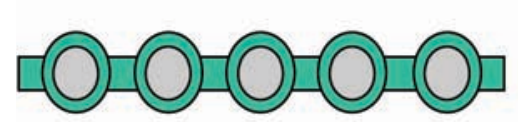

\section{Co-processed metallic tubes}

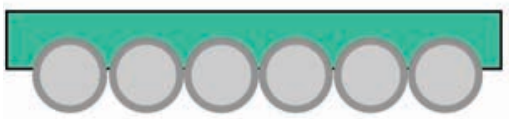

\section{Intimate contact metallic tubes}

Figure 43. Approaches for actively cooled composites.

An all composite actively-cooled structure would provide the lightest weight and highest temperature capability. However, numerous challenges exist, including optimum through-the-thickness conductivity, cooling containment, manifolding, oxidation protection, long life, and material compatibility. A photograph of an all composite actively cooled test article is shown in Figure 44. 


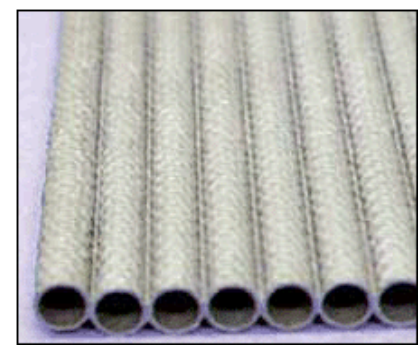

Figure 44. Photograph of an all composite actively cooled test article.

\section{B. Acreage TPS and Aeroshell}

There are several approaches to acreage TPS on hypersonic vehicles. One is an insulated structure, as used on the space shuttle orbiter. A standoff TPS approach as used on the X-33 is another approach. The standoff approach utilizes internal insulation below the outer surface. Finally, a load bearing aeroshell could be utilized.

\section{Insulated Structure}

An insulated structure has successfully been used on the space shuttle orbiter for years. The insulators, consisting of tiles and blankets, are attached directly to the cold structure to form the outer mold line. The insulation transfers the aero loads to the structure. There is a strain isolation pad (SIP) required between the tiles and aluminum structure due to the different thermal expansion of the two materials. The insulation is segmented (individual tiles), and each tile is on the order of around 6 in. $x 6$ in. Figure 45 shows a photograph of STS-114, with an excellent view of the tile insulation system. (As a note, the lighter color wing leading edges were replaced prior to the flight and had not yet experienced a re-entry.)

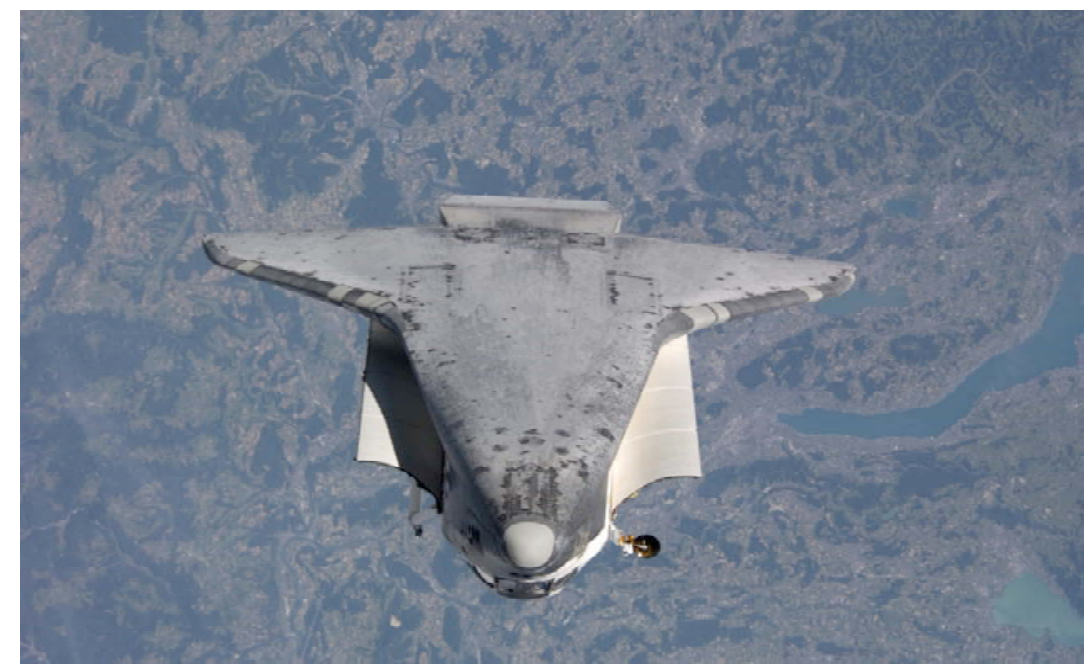

Figure 45. Photograph of STS-114 and the tile insulation system.

\section{NASA Ames Advanced Tile}

An improved tile has been developed by NASA, called TUFROC (toughened uni-piece reinforced oxidation resistance composite). It has a higher temperature capability $\left(3086^{\circ} \mathrm{F}\right)$ than the highest temperature tiles currently available $\left(2690^{\circ} \mathrm{F}\right)$. The tile consists of a carbonaceous cap composed of ROCCI (refractory oxidation-resistant ceramic carbon insulation) which provides dimensional stability to the outer surface, and a fibrous inner layer which provides optimal insulation of the substructure. The higher temperature capability of the tile may permit its use on some leading edges or nose caps. Arc-jet testing of the TUFROC has been performed and the surface is relatively non-catalytic. [10]

\section{EADS Astrium Flexible External Insulation}

Blanket insulation is used on much of the upper surface of the space shuttle orbiter. There has been some effort to improve the state-of-the-art of blanket insulations. Work has been performed by EADS Astrium (Europe) to improve their flexible external insulation (FEI) with both new high emittance coatings for improved 
stability and a less toxic waterproofing for both initial and re- waterproofing [11]. A photograph of the FEI insulation is shown in Figure 46.

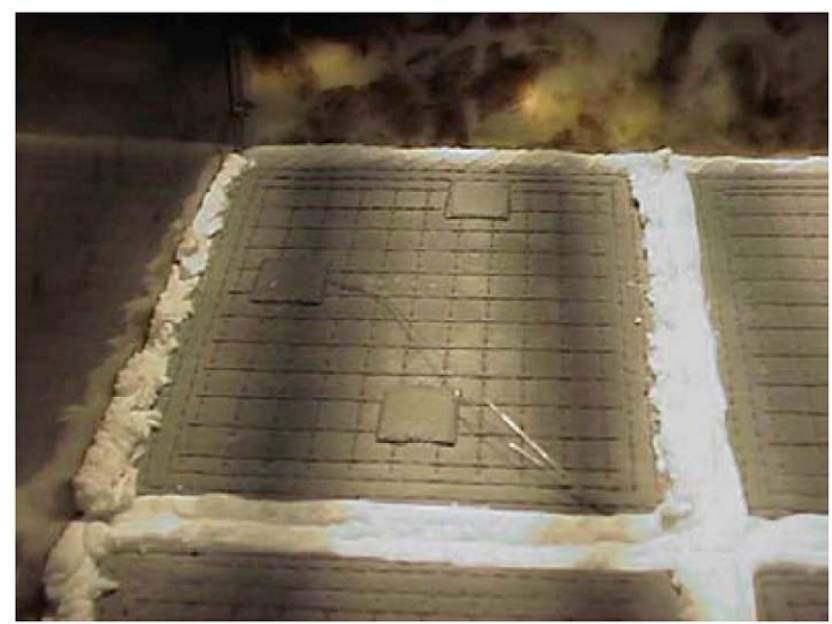

Figure 46. Photograph of repaired EADS Astrium FEI insulation [11].

Boeing Conformal Reusable Insulation

Boeing has developed a pair of conformal reusable insulations (CRI) for potential use on both windward and leeward surfaces. The Type I insulation has a maximum use temperature of $1,800^{\circ} \mathrm{F}$ for multi-use and $2,000^{\circ} \mathrm{F}$ for single use. The Type II insulation has a maximum use temperature of $2,200^{\circ} \mathrm{F}$ for multi-use and $2,400^{\circ} \mathrm{F}$ for single use.

\section{Stand-off TPS}

The stand-off TPS approach can be utilized on a cold or warm structure. One advantage of the stand-off TPS is that the outer aeroshell may have a different contour than the support structure. The sub-structure on the X-33 that supported the metallic TPS which formed the aeroshell is shown in Figure 47. The TPS panels, shown in Figure 48, are attached to stand-off brackets to create the desired aeroshell. The critical challenge with this approach is to transfer the aero loads, but not the thermal loads, to the structure. As with insulating tiles, the panels are segmented, but are much larger, around $18 \mathrm{in.} x 18 \mathrm{in}$. Metallic TPS is limited to regions where the use temperatures are in the range of $1800^{\circ} \mathrm{F}$, depending on the metallic alloys used. Numerous papers have been written concerning metallic TPS both in the US and Europe [12-16]. For hypersonic vehicles, there is often the need for higher use temperature acreage TPS, thus giving rise to the desire for a CMC TPS. In the US, metallic TPS is at a higher TRL than CMC TPS, while in Europe, CMC TPS is at a higher TRL than metallic TPS.

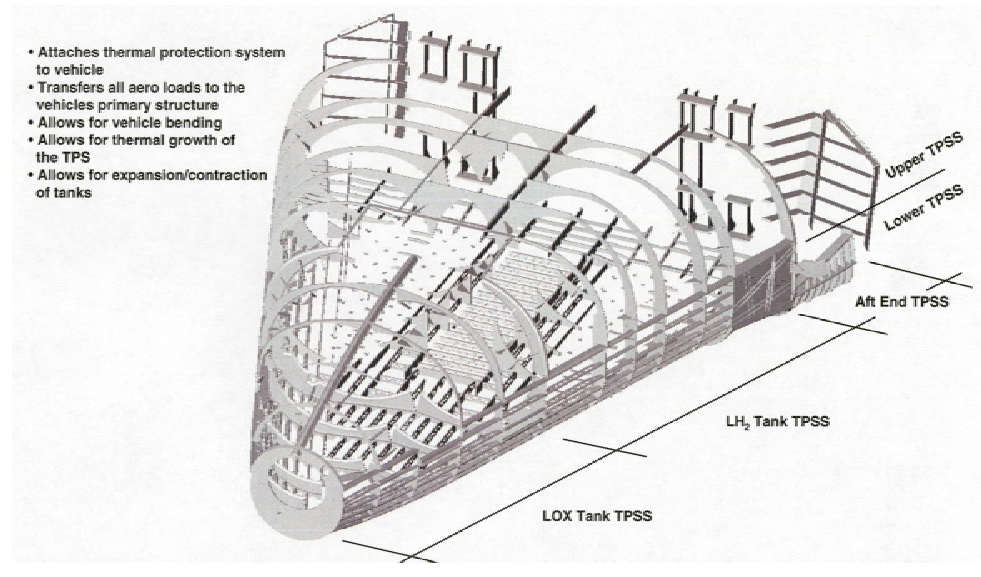

Figure 47. Schematic drawing of the structural layout of the X-33 RLV illustrating the support structure utilized for stand-off TPS. 


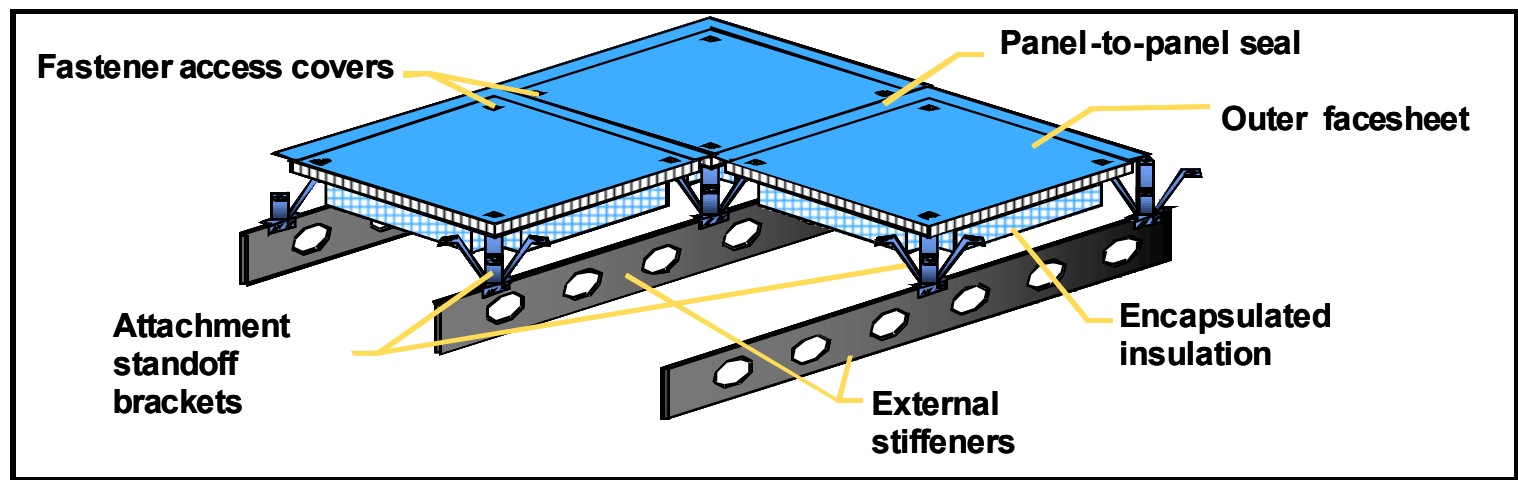

Figure 48. Schematic drawing of X-33 metallic TPS illustrating stand-off TPS attachment to sub-structure.

A ceramic matrix composite (CMC) stand-off TPS is illustrated in Figure 49 [17]. An external CMC panel with oxidation protection forms the aeroshell and the stand-off TPS includes an internal insulation. The insulation could be an efficient high temperature fibrous insulation. High temperature seals and an attachment are used to attach this external CMC panel to the internal structure. The primary challenge with any stand-off TPS is attaching the external panel to the substructure and transferring aero and pressure loads, but not thermal loads. In addition, the entire system must withstand acoustic and vibration loads.

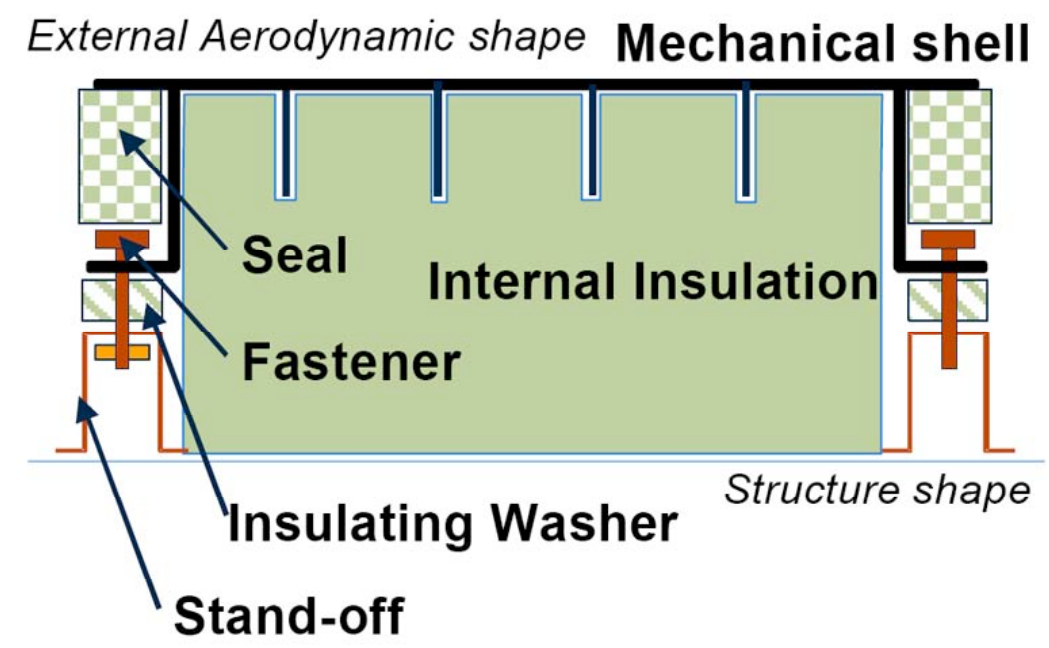

Figure 49. Schematic drawing of SPS CMC shingle TPS [17].

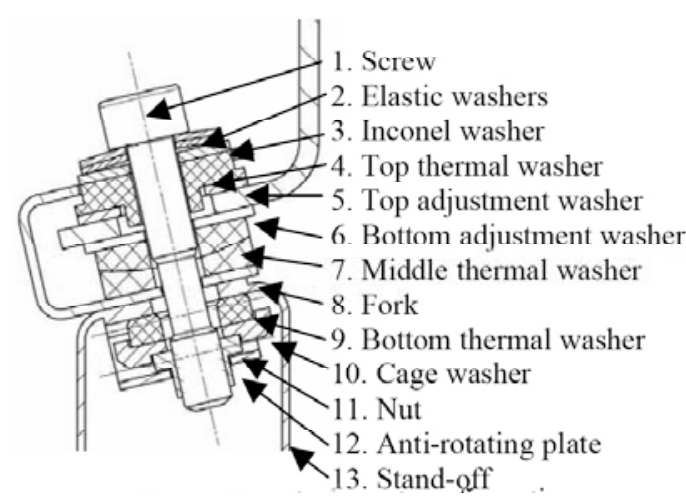

Figure 50. Schematic drawing of SPS shingle TPS attachment mechanism to the substructure [19]. 


\section{Snecma Propulsion Solide Shingle CMC TPS}

Snecma Propulsion Solide (SPS) (Bordeaux, France) has developed a CMC shingle TPS, separating the mechanical function and the thermal function. [17-19] The mechanical function components, the CMC shell, the fasteners, and the stand-offs, have good mechanical properties, but are not optimized to minimize heat transfer. The thermal function components, the internal insulation, the seals, and the insulating washers, are not intended to be load bearing, but are very efficient thermal insulators. The TPS has a total system mass of $3.7 \mathrm{lb} / \mathrm{ft}^{2}$. The attachment approach is shown in Figure 50. The attachment enables expansion mismatches between the CMC shingle (panel) and the structure by adapted flexibility of the stand-off, prevents large CMC deformation through sufficient stiffness, and transfers loads from the CMC panel to the structure. The attachment is designed for easy replacement with a portion of the attachment integrated with the CMC panel, and a portion integrated with the structure. SPS has fabricated a CMC shingle TPS array and has exposed it to mechanical, dynamic (modal, vibration, and acoustic) (Figure 51), thermal, thermal-mechanical, MMOD, and arc-jet testing (see Figure 51). The array is 31.5 in. x 17 in., with the CMC 0.039-in. thick, and was fabricated with one main panel and one secondary panel, allowing a linear seal to be tested. The total arc-jet testing time was equivalent to 11 reentries.

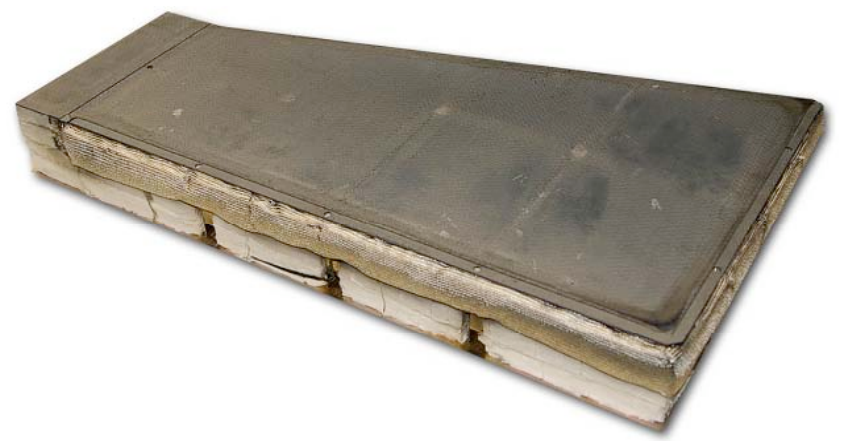

Figure 51. SPS CMC TPS array for mechanical, dynamic, thermal, and thermal-mechanical testing.

SPS also fabricated and tested two test articles to address the interface between a leading edge and the shingle TPS. These test articles were subjected to arc-jet testing. The maximum temperature measured on the flat panel behind the leading edge was $2192^{\circ} \mathrm{F}$, while the temperature was maintained below $230^{\circ} \mathrm{F}$ at the structure side, i.e. the interface between the structure and the stand-offs, demonstrating the thermal efficiency of the concept. The flat array in Figure 52 is 13.4 in. x 13.4 in., with the CMC 0.039-in. thick and was tested at the EADS Bordeaux SIMOUN arc-jet facility. Two linear seals were tested between panels, with a 'triple point' at the panel intersection. A photograph of the array during arc-jet testing is shown in Figure 52. The objective of the testing was to investigate the effects of steps and gaps at the seal. Eleven tests were conducted with different step and gap configurations. A curved test article is shown in Figure 53 during and after arc-jet testing at the Scirocco facility at CIRA in Italy. It was 23.6 in. x 16 in., with the CMC again 0.039 -in. thick, and a radius of 9.8 in. Again, two liner seals were tested with a 'triple point' at the panel intersection. The purpose of this testing was to evaluate the seal at the leading edge/panel interface as well as orienting the seal in the flow direction. Assembly and disassembly with access only to the outer surface was also demonstrated.

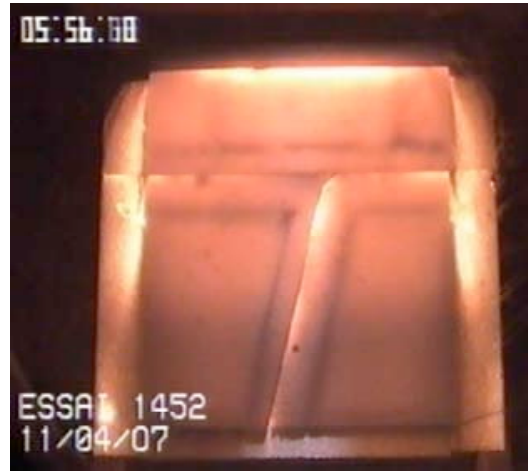

Figure 52. Snecma Propulsion Solide CMC TPS array during arc-jet testing. 

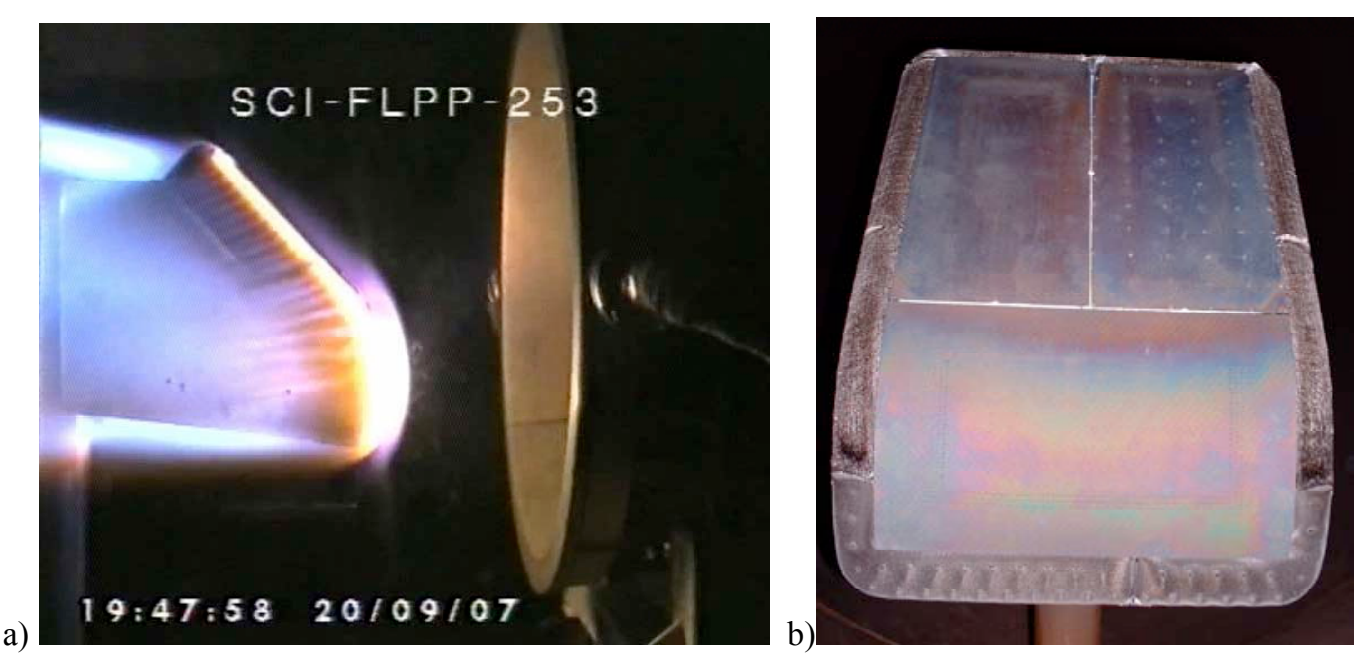

Figure 53. Snecma Propulsion Solide CMC TPS array a) during and b) after arc-jet testing.

\section{Internal Insulation}

Internal insulation is required for the stand-off TPS to reduce the heat load to the substructure. The internal insulation should be light-weight, flexible, and have a high heat capacity and low thermal conductivity. It must also be capable of long duration flight at elevated temperatures, implying that it is either non-oxidizing or protected from any oxidizing environment. High temperature fibrous insulation is often used as the internal insulation.

MT Aerospace Internal Multi-screen Insulation (IMI)

A more efficient insulation is a high temperature multi-layer insulation (MLI), with reflective layers separated by layers of fibrous insulation. MT Aerospace (Augsburg, Germany) has developed two different high temperature MLI's, referred to as Internal Multiscreen Insulation (IMI), one for use at $1832^{\circ} \mathrm{F}$ and one for use up to $2912^{\circ} \mathrm{F}$ [20]. The medium temperature MLI $\left(1832^{\circ} \mathrm{F}\right)$ utilizes Nextel 312 fabric for containment of the MLI, while the high temperature version utilizes Nextel 440 fabric. A schematic diagram of the medium temperature IMI utilizing nanoporous material (NPM) as the cold side insulation is shown in Figure 54.

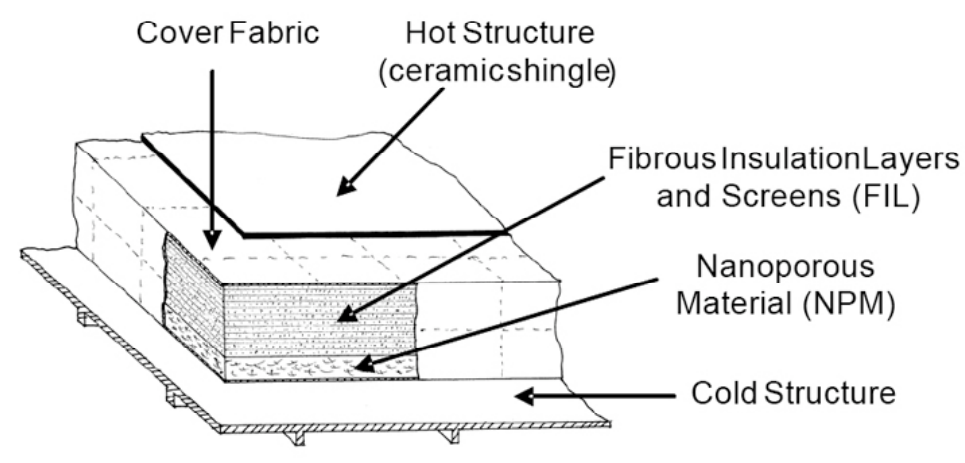

Figure 54. Schematic drawing of the MT Aerospace medium temperature IMI [20].

Steve Miller \& Associates Research Foundation Opacified Fibrous Insulation

An alternative to the MLI is an opacified fibrous insulation (OFI), developed by Steve Miller and Associates Research Foundation (SMARF) (Flagstaff, AZ). The OFI is a flexible insulation system consisting of opacified fibrous insulation felts quilted between layers of high temperature fabric. Combinations of opacified silica/alumina/zirconia felts can be used up to $3000^{\circ} \mathrm{F}$. The standard OFI consists of opacified alumina and silica felts, with a continuous use temperature of $2700^{\circ} \mathrm{F}$, encased in Nextel ${ }^{\mathrm{TM}}$ fabric cloth. The nominal combined density of a 1-in-thick blanket in this configuration is $18 \mathrm{lb} / \mathrm{ft}^{3}$ including fabric and thread, with an areal density of $1.5 \mathrm{lb} / \mathrm{ft}^{2}$, but density can be varied from $6-24 \mathrm{lb} / \mathrm{ft}^{3}$. The thermal conductivity of the fibrous insulation is a 
function of temperature and pressure. A higher air pressure increases the effective thermal conductivity, as can be seen in Figure 55.

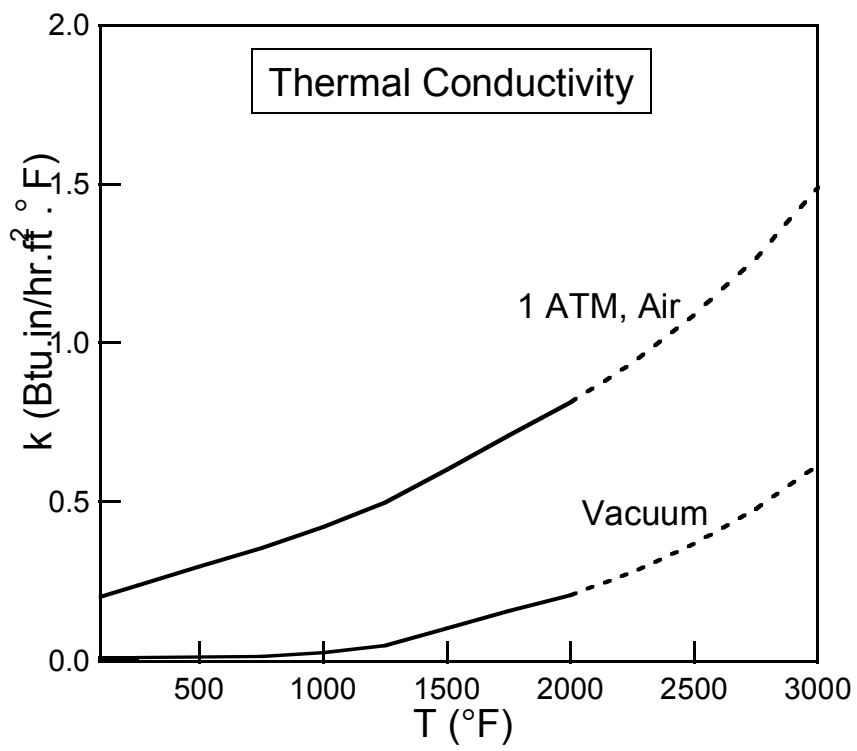

Figure 55. Thermal conductivity of the SMARF OFI as a function of temperature illustrating the impact of atmospheric pressure.

\section{Load Bearing Aeroshell}

A load bearing aeroshell carries the aerodynamic and vehicle axial loads. Insulation may either be incorporated in the structure or separate, below the aeroshell. This type of aeroshell has the potential for reduced weight. The image in Figure 56 shows the DARPA/Air Force Falcon HTV-2 vehicle, which utilizes a C/C aeroshell. [21-22]

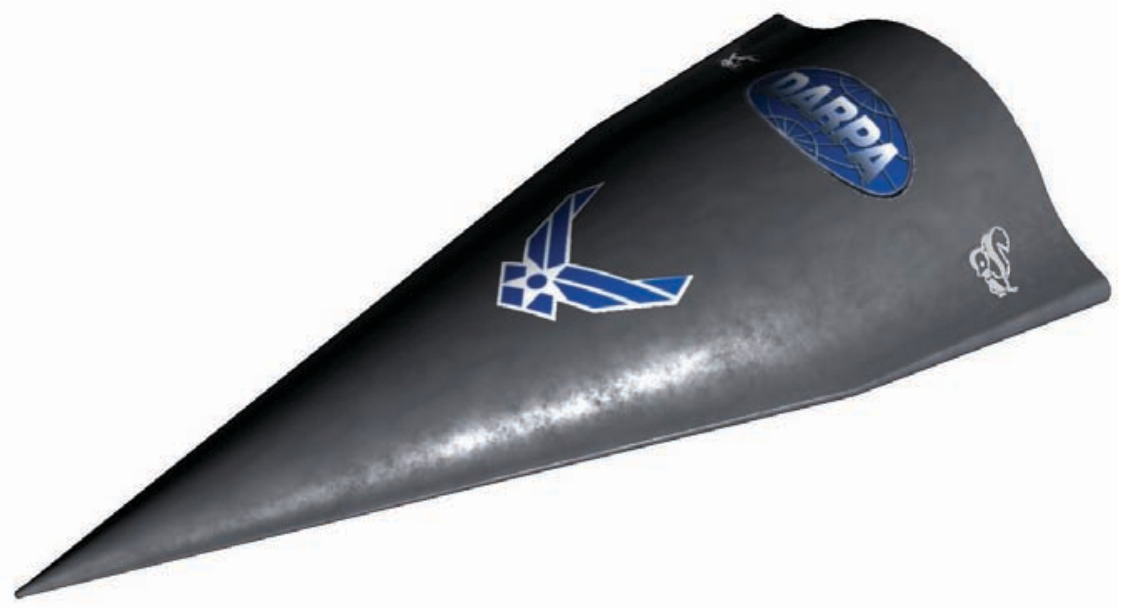

Figure 56. DARPA/Air Force Falcon HTV-2 vehicle, which utilizes a C/C aeroshell.

UK Ministry of Defense Sustained Hypersonic Flight Experiment

Another example of a load bearing aeroshell is the $\mathrm{C} / \mathrm{SiC}$ aeroshell for the UK Ministry of Defense sponsored Sustained Hypersonic Flight Experiment (SHyFE), shown in Figure 57. [23-25] The objective of this flight experiment is to design and fly a prototype ramjet capable of sustained hypersonic flight. The vehicle weighs approximately $30 \mathrm{~kg}$, and is $1.5 \mathrm{~m}$ long, with a diameter of $7 \mathrm{in}$. The aeroshell is being fabricated by MT Aerospace (Augsburg, Germany) utilizing chemical vapor infiltration (CVI). Fuel flows in an annulus between two $\mathrm{C} / \mathrm{SiC}$ tubes. The fin roots are bonded to the aeroshell. Many of the attachments utilized on previous designs have been eliminated in the approach used here. 


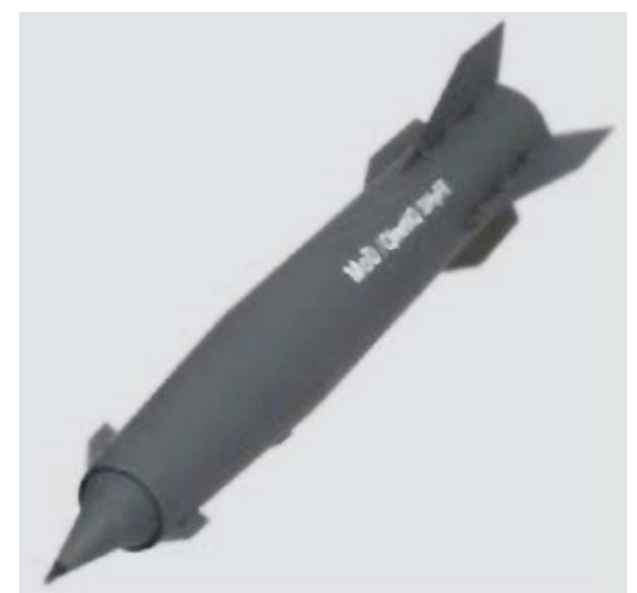

Figure 57. C/SiC load bearing aeroshell utilized on the SHyFE [24].

\section{Structurally Integrated TPS}

The final TPS approach discussed is a structurally integrated TPS, as illustrated in Figure 58. Here, the outer and inner walls carry the airframe loads, with the outer wall operating hot and the inner wall insulated. It is thermally integrated, has a higher structural efficiency, and is potentially lower maintenance. The outer surface is a robust, high-temperature material. The wall thickness helps provide stiffness and the large integrated structure eliminates/reduces surface gaps and steps and also provides low part count. Though there may be some advantages to this approach, it should be considered the lowest TRL of the approaches discussed here.

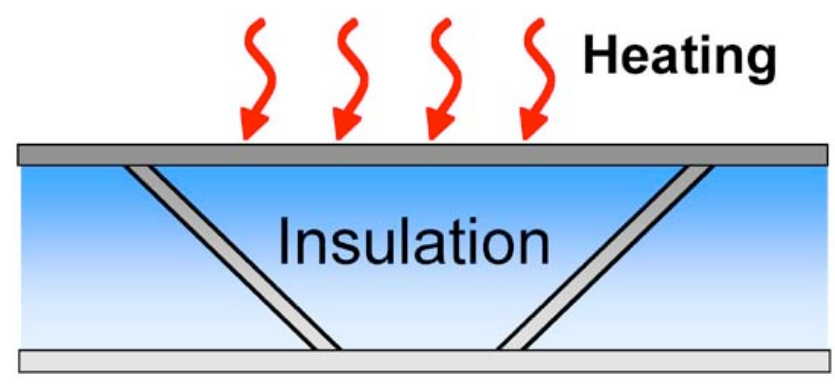

Figure 58. Schematic drawing of structurally integrated TPS.

\section{Control Surfaces}

Control surfaces are required on vehicles to control the vehicle during flight. Figure 59 illustrates a hypersonic vehicle with elevons and rudders. For hypersonic vehicles, drag is very important, thus driving toward thin control surfaces. There are several different approaches for designing and fabricating control surfaces, including insulated, hot structure, and hybrid.

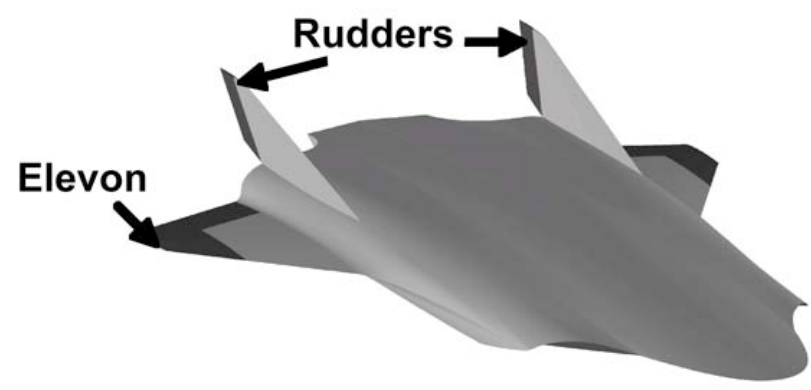

Figure 59. Image of hypersonic vehicle showing rudders and elevons, two types of control surfaces. 
An excellent paper on control surface requirements, design, and validation has been written by Steinacher, et al. [26], some of which is summarized here. The requirements for control surfaces are a function of the vehicle design and the entire mission, from pre-takeoff ground operations to post-landing cool down. For some insulated structures, the highest temperatures are reached after landing/touchdown. Reusability requirements include integrity of the oxidation coating and lifetime of the various components. It is important to ensure that the life of the individual components exceeds the life of the control surface or that it is designed for easy replacement. The geometry of the control surface is impacted directly by flight control (aerodynamics) and vehicle interfaces. Mass, stiffness, and structural integrity have an indirect impact on the geometry requirements. The mechanical requirements are generated by the pressure differential between the windward and leeward surfaces, while the thermal requirements include the maximum temperature, thermal stresses, oxidation (active and/or passive), interfaces with cold structures such as actuators, and thermal radiation from opposing surfaces. Functional requirements such as number of cycles and flap actuation also impact the requirements. As an example, the control surfaces on the X-38 reentry vehicle had a deflection range of $\pm 20^{\circ}$, a rate of $0.1-0.7 \mathrm{~Hz}$, and were designed for 874 cycles. The approach used to attach control surfaces to a vehicle also impact design. For example, control surfaces could be attached behind the vehicle, underneath the vehicle, or at the trailing edge. Static and dynamic seals are also required around hinge lines, around the actuation rod, and at supports to prevent sneak flow into the vehicle. Some of the requirements can be validated by analysis, some by review and inspection, while some must be validated by testing. [26]

\section{Insulated Control Surface}

Insulated control surfaces have been successfully used on the Space Shuttle Orbiter for many years. Some of the advantages of an insulated control surface include its suitability for very large structures and its minimal thermal expansion issues. Disadvantages include weight, low thermal margin because the structure is a low temperature structure, and thick cross-sections [27]. In Figure 60, the image on the left shows a metal or PMC control surface with tile on it as insulation. The tiles can also be seen on the picture of the Orbiter elevons. [27]
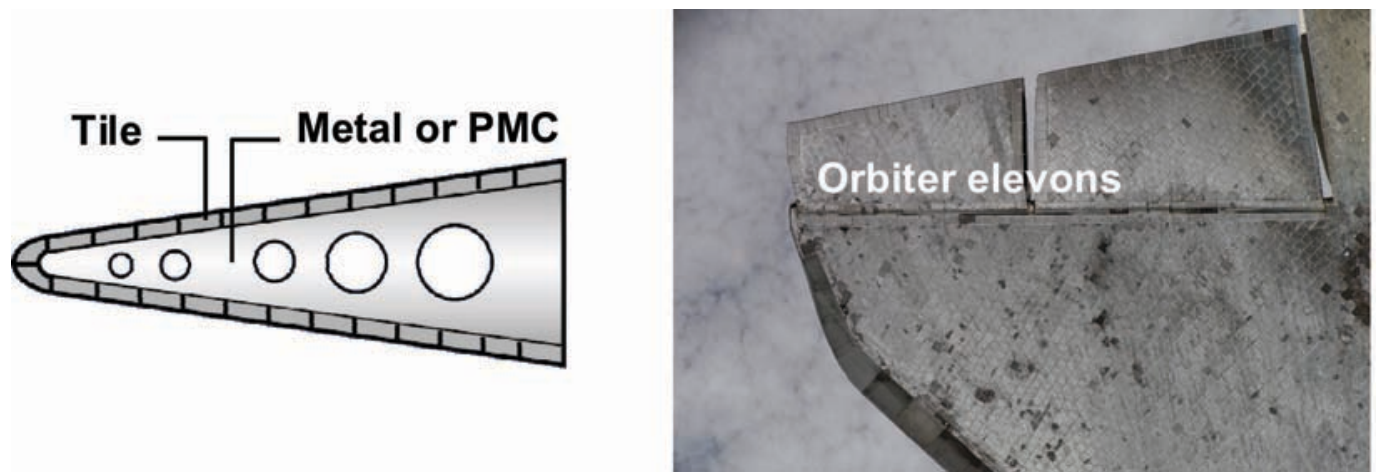

Figure 60. Schematic [27] and photograph (Space Shuttle Orbiter) of insulated control surface.

\section{Ceramic Matrix Composite Hot Structure Control Surface}

The CMC hot structure control surface approach provides the lowest weight and thinnest cross-section, minimal thermal expansion mismatch problems, and a good thermal margin. This approach is also advantageous because of its sufficient strength and stiffness and there is no external insulation required. Disadvantages to this approach include the high manufacturing and tooling costs for the box structure and scale up. This approach may not be recommended for very large structures. Its repair capability is limited and the manufacturing risk is high in cases of production failure or damage. Access for coating, inspection, and maintenance of internal areas is also a disadvantage. [27] A mechanically assembled CMC control surface can be fabricated and assembled using multiple smaller parts. Advantages to this approach are that the tooling is relatively simple and damaged components can be replaced without a complete scrap of the entire control surface. A disadvantage to this approach is that tolerance buildup can be problematic in assembly of numerous separate parts. High part count is another disadvantage of this approach. 
General Electric Energy Ceramic Composite Products, LLC and Materials Research \& Design C/SiC Body Flap

A C/SiC body flap was fabricated by General Electric Energy Ceramic Composite Products (GECCP), LLC (Newark, DE) and designed by Materials Research \& Design (MR\&D) (Wayne, PA). This control surface used $\mathrm{C} / \mathrm{SiC}$ fastened joints and a thin ply torque tube and box structure along with gusset members for load transfer. Figure 61 shows the individual parts and the fasteners used for assembly, and Figure 62 shows a photograph of the assembled body flap.

a)
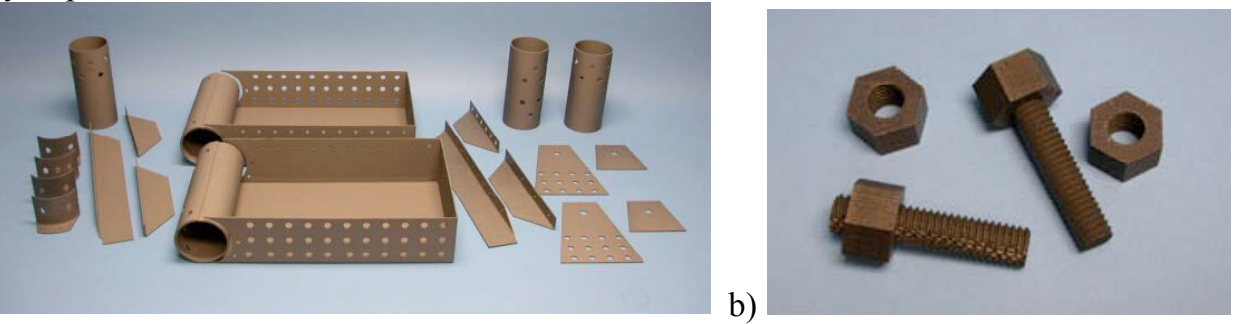

Figure 61. Photographs of a) individual parts used to assemble control surface, and b) fasteners used for the assembly.

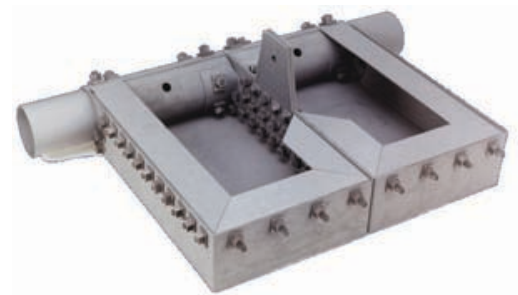

Figure 62. Photograph of a mechanically assembled body flap (GECCP \& MR\&D).

\section{MT Aerospace C/SiC Body Flap}

MT Aerospace developed C/SiC body flaps for the X-38 re-entry vehicle, shown in Figure 63. [28-29] The body flap was fabricated entirely out of CMC's, including fasteners and bearings. Several key technologies were developed and qualified as part of the body-flap development. These include:

- Manufacturing of large $\mathrm{C} / \mathrm{SiC}$ structures

- Manufacturing of thick $\mathrm{C} / \mathrm{SiC}$ structures

- Oxidation protection

- High-temperature bearings

- Highly loaded joints with ceramic bolts and nuts

- Interface of cold metallic to hot ceramic parts

- High temperature dynamic seals

The bearing assembly was qualified via both hot and cold testing. The full scale body flaps were qualified for flight under ascent and descent vibration, thermal, and static pressure loads. MT Aerospace has more recently updated the body flap design for the Pre-X flight demonstrator [30].

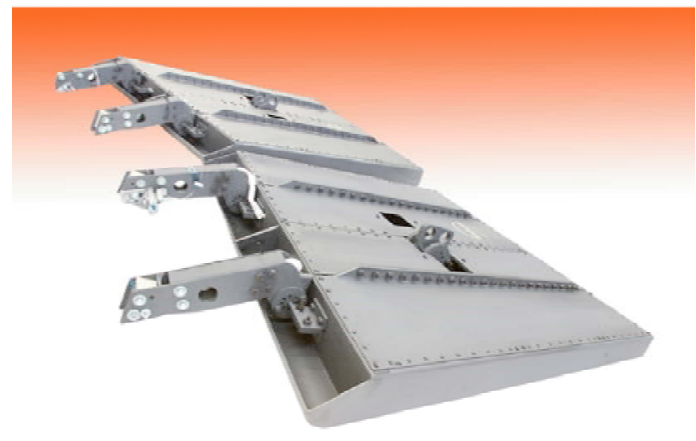

Figure 63. Photograph of the X-38 C/SiC body flaps fabricated by MT Aerospace [30]. 


\section{Integrated Fabrication}

An integrated fabrication is an alternative fabrication approach. Advantages to this approach include fewer joints and better mechanical performance. Disadvantages include the complex tooling, the associated fabrication expense, and the risk of damage during fabrication. An integrated fabrication approach has been demonstrated by MT Aerospace (Augsburg, Germany) on a $\mathrm{C} / \mathrm{SiC}$ body flap segment, shown in Figure 64. The part was fabricated utilizing a 2D-prepreg of carbon fabric that was cured and pyrolyzed and then further densified via a chemical vapor infiltration (CVI) process. The integrated fabrication permitted the part to be fabricated without any fasteners that would increase mass. [30]

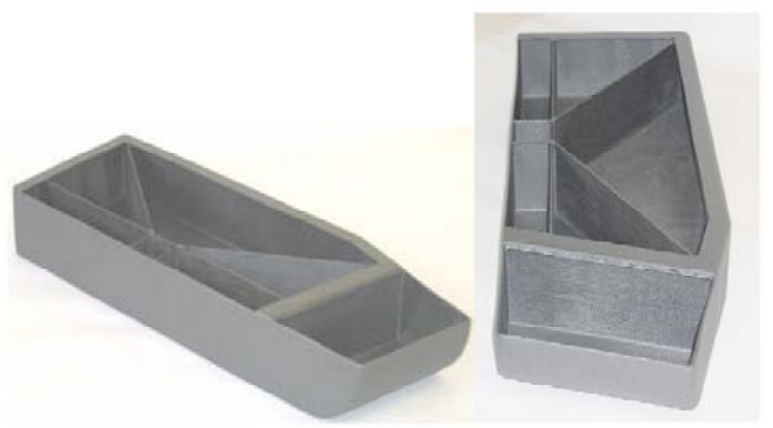

Figure 64. Photograph of the side and top view of an integrated body flap segment demonstration [30].

\section{Hybrid Control Surface}

Hybrid control surfaces combine a CMC with a lower temperature material such as titanium or a superalloy. Advantages of a hybrid control surface approach are that manufacturing may be more affordable for large structures. Also, it may not require TPS on the upper surface and the CMC leading and trailing edges can be replaced if they are damaged. Disadvantages are the thermal mismatch between the cool structure (metal/PMC) and the CMC. The weight increase over an all CMC control surface can amount to 30-40\% [27]. In addition, the box structure's insulation can lead to increased thickness, leading to either a reduced structure thickness and smaller moment of inertia or a thicker cross-section.

\section{$\underline{X}-43$ Hybrid Control Surface}

The X-43 used the hybrid control surface approach, as shown in Figure 65. A Haynes 230 superalloy was used for the structure and $\mathrm{C} / \mathrm{C}$ was used for the leading edges. There was no insulation on the control surface. A spindle connected the control surface to an actuator in the fuselage. This was a relatively small control surface structure, on the order of 2 feet.

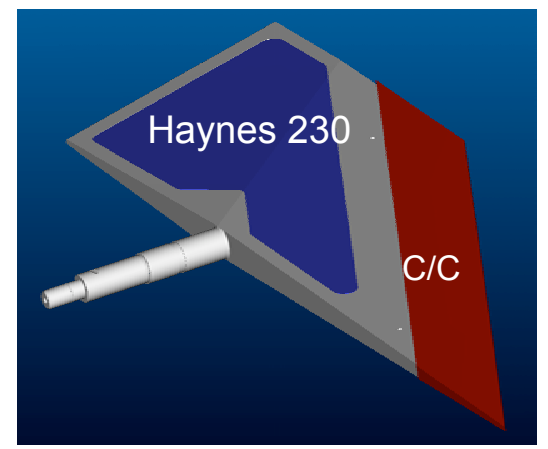

Figure 65. Schematic diagram of the $\mathrm{X}-43$ hybrid control surfaces.

Dutch Space X-38 Hybrid Control Surface

Dutch Space (Leiden, The Netherlands) has designed and fabricated hot metallic control surfaces (rudder) for the X-38 flight vehicle, Figure 66. The initial rudder was fabricated out of PM-1000, with a use temperature up to $2190^{\circ} \mathrm{F}$. When the requirements for the rudder changed, Dutch Space designed and qualified a hybrid Ti/ceramic 
tile rudder in a time period of 1 year. For the crew return vehicle (CRV), a hybrid metallic/CMC rudder was planned. [31]

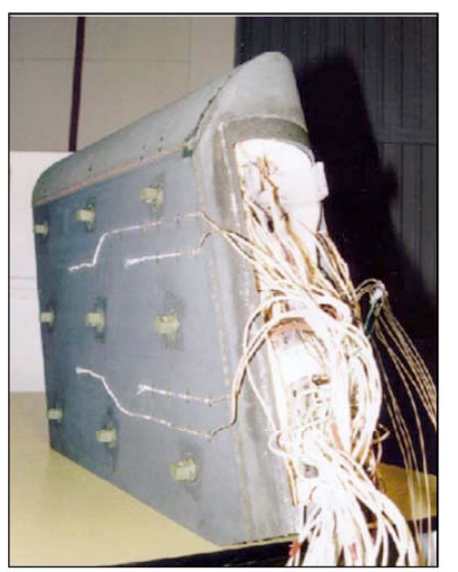

Figure 66. Photograph of Dutch Space hot rudder designed for the X-38 [31].

\section{Key Technical Challenges}

CMC's are the materials that will enable many of the components on air-breathing hypersonic vehicles. CMC's will be used for leading edges, acreage, hot structures, and in the propulsion system. For most CMC structures, there are two primary materials and structures technical challenges: fabrication and environmental durability.

\section{A. Fabrication}

There are several processes for fabricating $\mathrm{C} / \mathrm{C}, \mathrm{C} / \mathrm{SiC}$, and $\mathrm{SiC} / \mathrm{SiC}$, each having their own challenges. Small coupons can be fabricated with relative consistency. However, a coupon built today may or may not be similar to one that is built six months from now. The key point is that a state-of-the-art material is not the same as a state-of-the-art structure. Just because the material can be fabricated, does not at all guarantee that a structure can successfully be fabricated and that it would survive the required mission life. This is illustrated in Figure 67, showing the simplicity of a CMC test coupon versus the fabrication complexity of a CMC body flap.
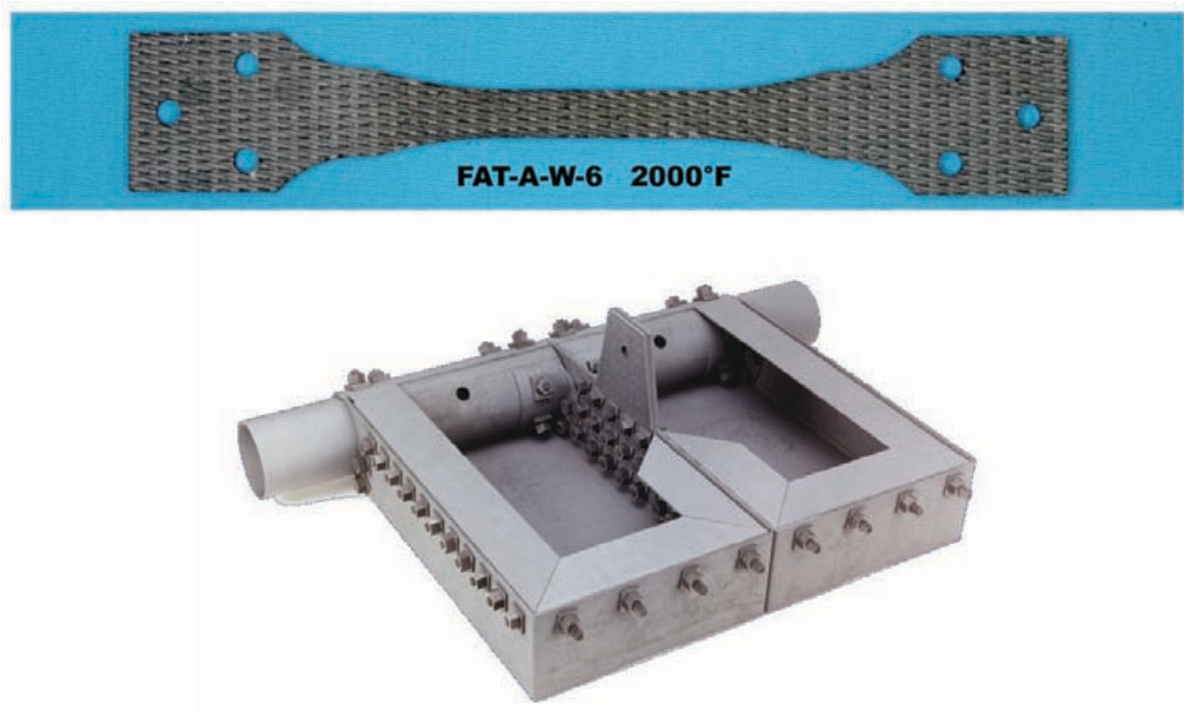

Figure 67. Photograph of a material test coupon and a CMC body flap test article.

The following fabrication challenges, again process dependent, arise in going from a small material coupon to a large flight structure.

- Thickness (density uniformity through out the structure) 
- Complex curvature

- Large scale

- Low interlaminar properties

- Delaminations

- Critical flaw size

- Non-destructive inspection

- Tooling

- Assembly methods and tolerances

- Reproducibility

- Fabrication modeling

- Manufacturability of structures design

- Affordable (cost \& schedule) fabrication techniques

Meeting the flight requirements is another challenge that impacts the structure maturity on a component. Operation has a significant impact on the ability to use these materials as structures on flight vehicles. Challenges to consider for flight requirements include:

- Thermal loads

- Thermal gradients

- Mechanical loads

- Acoustic and vibration loads

- Pressure (oxidation)

- Combined loads

- Number of cycles

During flight, many of the loads are combined, thus generating potentially severe thermal-structural loading.

\section{B. Environmental Durability}

The primary environment durability challenge is oxidation resistance, which has a major impact on mission life. Oxidation of CMC's was discussed earlier in this paper. The number of cycles required under combined loads, inspection and repair, and the ability to predict mission life all present challenges. Figure 68 shows a failed test article after severe oxidation during an arc-jet test.

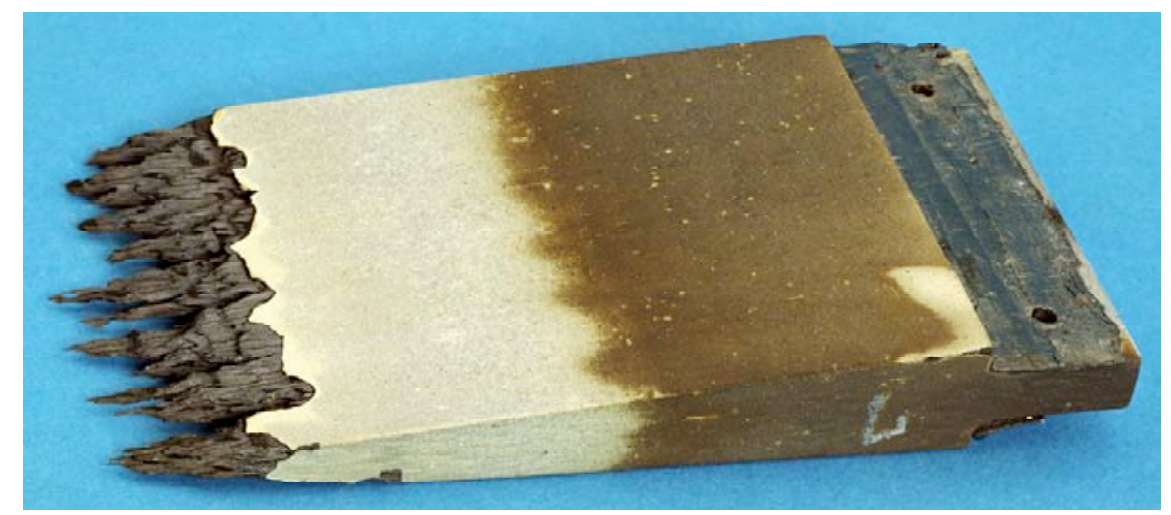

Figure 68. Failed test article after severe oxidation during an arc-jet test.

\section{Concluding Remarks}

Hypersonic air-breathing vehicles will require moving beyond an insulated aluminum "airplane", such as the Space Shuttle Orbiter, to a vehicle with multiple TPS and hot structure approaches. The ability to build and fly these vehicles successfully will depend on the ability to use multiple types of CMC structures, but only after solving the environmental durability and fabrication challenges.

\section{References}

1. H. Hald, M. Ortelt, I. Fischer, D. Greuel, and O. J. Haidn, "Effusion Cooled CMC Rocket Combustion Chamber", AIAA/CIRA $13^{\text {th }}$ International Space Planes and Hypersonics Systems and Technologies, CIRA, Italy, AIAA-2005-3229, May 2005. 
2. Earl Thornton, “Thermal Structures for Aerospace Applications”, AIAA Press, 1996.

3. Ronald. K. Clark, George. R. Cunnington, Jr., and Karl. E. Wiedemann, "Determination of the Recombination Efficiency of Thermal Control Coatings for Hypersonic Vehicles", Journal of Spacecraft and Rockets, Vol. 32, No. 1, Jan.-Feb. 1995.

4. G. Hilfer, "Ceramic Thermal Protection Materials - How Far can We Go? New Aspects on the Oxidation Behavior During Re-entry Flight", 2 ${ }^{\text {nd }}$ International Symposium on Reentry Vehicles and Systems, Arcachon, France, March 26-29, 2001.

5. C. W. Ohlhorst, et al., "Development of X-43A Mach 10 Leading Edges," $56^{\text {th }}$ International Astronautical Congress, Fukuoka, Japan, October 2005, IAC-05-D2.5.06.

6. H. Kevin Rivers and David E. Glass, "Advances in Hot Structures Development", $5^{\text {th }}$ European Workshop on Thermal Protection Systems and Hot Structures, Noordwijk, The Netherlands, May 17-19, 2006.

7. D. E. Glass and C. J. Camarda, "Preliminary Thermal/Structural Analysis of a Carbon/Carbon RefractoryMetal Heat-Pipe-Cooled Wing Leading Edge," Thermal Structures and Materials for High-Speed Flight, edited by E. A. Thornton, Vol. 140, Progress in Astronautics and Aeronautics, AIAA, New York, 1992, pp. 301-322.

8. D. E. Glass, M. A. Merrigan, J. T. Sena, "Fabrication and Testing of Mo-Re Heat Pipes Embedded in Carbon/Carbon," NASA CR-1998-207642, March 1998.

9. D. E. Glass, M. A. Merrigan, J. T. Sena, and R. S. Reid, "Fabrication and Testing of a Leading-Edge-Shaped Heat Pipe," NASA CR-1998-208720, October 1998.

10. David A. Stewart and Daniel B. Leiser, "Lightweight TUFROC TPS for Hypersonic Vehicles", $14^{\text {th }}$ AIAA/AHI Space Planes and Hypersonic Systems and Technologies Conference, Canberra, Australia, AIAA-2006-7945, November 2006.

11. J. Antonenko, U. Rieck, and H. Ritter, "Improvement of Flexible External Insulation Concerning ReUsability", $5^{\text {th }}$ European Workshop on Thermal Protection Systems and Hot Structures, Noordwijk, The Netherlands, May 17-19, 2006.

12. Max L. Blosser, "Fundamental Modeling and Thermal Performance Issues for Metallic Thermal Protection System Concept", AIAA Journal of Spacecraft and Rockets, Vol. 41, No. 2, March-April 2004.

13. John T. Dorsey, Carl C. Poteet, Kathryn E. Wurster, and Roger R. Chen, "Metallic Thermal Protection System Requirements, Environments, and Integrated Concepts", AIAA Journal of Spacecraft and Rockets, Vol. 41, No. 2, March-April 2004.

14. Carl C. Poteet, Hasan Abu-Khajeel, and Su-Yuen Hsu, "Preliminary Thermal-Mechanical Suzing of a Metallic Thermal Protection System”, AIAA Journal of Spacecraft and Rockets, Vol. 41, No. 2, MarchApril 2004.

15. Wolfgang P. P. Fischer, "ULTIMATE: Metallic Thermal Protection System for Future RLV's - Design and Performance Verification Approach", SAE Technical Paper Series, 2004-01-2566, 35 ${ }^{\text {th }}$ International Conference on Environmental Systems, Colorado Springs, CO, July 2004.

16. J. Fatemo, S. Birjmohan, M. Rijkeboer, and M. C. M. Bakker, "Analysis and Testing of a Metallic Thermal Protection System of RLV Applications", $4^{\text {th }}$ International Symposium Atmospheric Reentry Vehicles \& Systems, Arachon, France, March 2005.

17. T. Pichon, P. Soyris, R. Barreteau, A. Foucault, J. M. Parenteau, and M. Lacoste, "Generic CMC Thermal Protection System Pre-Development for Reentry Demonstrator Vehicle", 2nd European Conference for Aerospace Sciences (EUCASS).

18. H. Coperet, P. Soyris, M. Lacoste, J Garnett, and D. Tidwell, "MMOD Testing of C-SiC Based Rigid External Insulation of the X-38 / CRV Thermal Protection System", IAC-02-I.3.06, 53 ${ }^{\text {rd }}$ International Astronautical Congress, October 2002, Houston, TX

19. T. Pichon, P. Soyris, A. Faucault, J.M. Parenteau, Y. Prel, and S. Guedron, "C/SiC Based Rigid External Thermal Protection System For Future Reusable Launch Vehicles: Generic Shingle, Pre-X / FLPP Anticipated Development Test Studies", $5^{\text {th }}$ European Workshop on Thermal Protection Systems and Hot Structures, Noordwijk, The Netherlands, May 17-19, 2006.

20. K. Keller, E. Pfeiffer, K. Handrick, S. Weiland, T. Ullmann, and H. Ritter, "Advanced High Temperature Insulations", $5^{\text {th }}$ European Workshop on Thermal Protection Systems and Hot Structures, Noordwijk, The Netherlands, May 17-19, 2006.

21. Steven H. Walker and Fredrick Rodgers, "Falcon Hypersonic Technology Overview", AIAA/CIRA $13^{\text {th }}$ International Space Planes and Hypersonics Systems and Technologies, CIRA, Italy, AIAA-2005-3253, May 2005.

22. David E. Glass, Ray Dirling, Harold Croop, Timothy J. Fry, and G. J. Frank, "Materials Development for 
Hypersonic Flight Vehicles", $14^{\text {th }}$ AIAA/AHI Space Planes and Hypersonic Systems and Technologies, Canberra, Australia, AIAA-2006-8122, Nov. 2006.

23. T. Cain and C. Walton, "The Sustained Hypersonic Flight Experiment", AIAA-2003-7030, December 2003.

24. G. Dadd, R. Owen, J. Hodges, and K. Atkinson, "Sustained Hypersonic Flight Experiment (SHyFE)", $14^{\text {th }}$ AIAA/AHI Space Planes and Hypersonic Systems and Technologies Conference, Canberra, Australia, AIAA-2006-7926, November 2006.

25. J. Goodman and P. Ireland, "Thermal Modelling for the Sustained Hypersonic Flight Experiment", $14^{\text {th }}$ AIAA/AHI Space Planes and Hypersonic Systems and Technologies Conference, Canberra, Australia, AIAA-2006-8071, November 2006.

26. A. Steinacher, H. Lange, S. Weiland, and S. Hudrisier, "Development of CMC Body Flap for Future ReEntry Vehicles", $58^{\text {th }}$ International Astronautical Congress, Hyderabad, India, Sept 24-28, 2007, IAC-07C2.4.01.

27. U. Trabandt, T. Schmid, and E. Werth, "CMC and Metallic Hot Structure Hybrid Components for RLV," $54^{\text {th }}$ International Astronautical Congress, Breman, Germany, 2003.

28. H. Pfeiffer and K. Peetz, "All-Ceramic Body Flap Qualified for Space Flight on the X-38", $53^{\text {rd }}$ International Astronautical Congress The World Space Congress - 2002", Houston, TX, Oct. 2002, IAF-02-I.6.b.01.

29. H. Pfeiffer and M Dogigli, "All-Ceramic Body Flap for the X-38: A Revolutionary Step Forward", $3^{\text {rd }}$ European Conference Structures and Technologies Challenges for Future Launchers, Strasbourg, Germany, Dec. 2001.

30. H. Lange, A Steinacher, K. Handrick, S. Weiland, D. Sygulla, S. Guedron, and T. Salmon, "Status of Flap Development for Future Re-Entry Vehicles (Pre-X)", $5^{\text {th }}$ European Workshop on Thermal Protection Systems and Hot Structures, Noordwijk, The Netherlands, May 17-19, 2006.

31. E. Mooij, Q. T. Vo, and J. W. P. I. Offerman, "Technology Status and Developments of Metallic Hot Structures and Thermal Protection Systems", $5^{\text {th }}$ European Workshop on Thermal Protection Systems and Hot Structures, Noordwijk, The Netherlands, May 17-19, 2006. 